\title{
REVIEW
}

Open Access

\section{A comparison of self-reported and device measured sedentary behaviour in adults: a systematic review and meta-analysis}

Stephanie A. Prince ${ }^{1,2^{*}}$ D , Luca Cardilli, ${ }^{3,4}$, Jennifer L. Reed ${ }^{1,5,6}$, Travis J. Saunders ${ }^{7}$, Chris Kite ${ }^{8,4}$, Kevin Douillette ${ }^{7}$, Karine Fournier ${ }^{9}$ and John P. Buckley ${ }^{4}$

\begin{abstract}
Background: Sedentary behaviour (SB) is a risk factor for chronic disease and premature mortality. While many individual studies have examined the reliability and validity of various self-report measures for assessing SB, it is not clear, in general, how self-reported SB (e.g., questionnaires, logs, ecological momentary assessments (EMAs)) compares to device measures (e.g., accelerometers, inclinometers).

Objective: The primary objective of this systematic review was to compare self-report versus device measures of SB in adults.

Methods: Six bibliographic databases were searched to identify all studies which included a comparable self-report and device measure of SB in adults. Risk of bias within and across studies was assessed. Results were synthesized using meta-analyses.

Results: The review included 185 unique studies. A total of 123 studies comprising 173 comparisons and data from 55,199 participants were used to examine general criterion validity. The average mean difference was -105.19 minutes/day ( $95 \%$ Cl: $-127.21,-83.17$ ); self-report underestimated sedentary time by $\sim 1.74$ hours/day compared to device measures. Self-reported time spent sedentary at work was $\sim 40$ minutes higher than when assessed by devices. Single item measures performed more poorly than multi-item questionnaires, EMAs and logs/diaries. On average, when compared to inclinometers, multi-item questionnaires, EMAs and logs/diaries were not significantly different, but had substantial amount of variability (up to 6 hours/day within individual studies) with approximately half over-reporting and half under-reporting. A total of 54 studies provided an assessment of reliability of a selfreport measure, on average the reliability was good $(I C C=0.66)$.

(Continued on next page)
\end{abstract}

\footnotetext{
* Correspondence: stephanie.princeware@canada.ca

'Division of Cardiac Prevention and Rehabilitation, University of Ottawa Heart Institute, Ottawa, Canada

${ }^{2}$ Centre for Surveillance and Applied Research, Public Health Agency of Canada, 785 Carling Avenue, Ottawa K1A 0K9, Canada

Full list of author information is available at the end of the article
}

(c) The Author(s). 2020 Open Access This article is licensed under a Creative Commons Attribution 4.0 International License, which permits use, sharing, adaptation, distribution and reproduction in any medium or format, as long as you give appropriate credit to the original author(s) and the source, provide a link to the Creative Commons licence, and indicate if changes were made. The images or other third party material in this article are included in the article's Creative Commons licence, unless indicated otherwise in a credit line to the material. If material is not included in the article's Creative Commons licence and your intended use is not permitted by statutory regulation or exceeds the permitted use, you will need to obtain permission directly from the copyright holder. To view a copy of this licence, visit http://creativecommons.org/licenses/by/4.0/. The Creative Commons Public Domain Dedication waiver (http://creativecommons.org/publicdomain/zero/1.0/) applies to the data made available in this article, unless otherwise stated in a credit line to the data. 


\begin{abstract}
(Continued from previous page)
Conclusions: Evidence from this review suggests that single-item self-report measures generally underestimate sedentary time when compared to device measures. For accuracy, multi-item questionnaires, EMAs and logs/diaries with a shorter recall period should be encouraged above single item questions and longer recall periods if sedentary time is a primary outcome of study. Users should also be aware of the high degree of variability between and within tools. Studies should exert caution when comparing associations between different self-report and device measures with health outcomes.
\end{abstract}

Systematic review registration: PROSPERO CRD42019118755

Keywords: Self-report, device, sedentary behaviour, systematic review

\section{Introduction}

Sedentary behaviour (SB) is considered a risk factor for chronic disease and premature mortality [1]. This area of enquiry has, therefore, gained much attention in the past decade with a dramatic increase in the amount of research and surveillance being performed [2]. Often the term sedentary is assumed as a general description for classifying people with low levels of physical activity (PA), but it is a distinct term referring to any wakeful state of sitting, lying or reclining where energy expenditure is $\leq 1.5$ metabolic equivalents (METs) [3]. It is, therefore, possible for people to be regularly physically active and yet have high levels of SB.

Ekelund et al. (2016) performed a large observational study to assess the interactions between SB and PA, and reported that the associated risk of prolonged sitting was nullified once individuals performed 60-75 minutes per day of moderate-to-vigorous intensity physical activity (MVPA) [4]. Current PA guidelines promote a threshold of 150 minutes of MVPA per week [5] which is far less than the aforementioned 60-75 minutes/day. Very few adults today (especially in high income countries) meet these MVPA guidelines and most spend the majority of their days sedentary [6-8]. This suggests that large proportions of adults, even those who exercise regularly and within the PA guidelines, could still be exposed to the health risks of prolonged sitting.

As with PA [9], the largest challenge to the validity of the link between SB and health is the measures. While direct measurement of SB using accelerometers and inclinometers has grown increasingly popular, the cost-toutility ratio has remained fairly high with often prohibitive device and resource costs and a required proximity to respondents $[10,11]$. Monitoring of SB by self-report remains the most practical means for most national surveillance systems [12] and research studies; contextual information that is often missing from device-assessed SB such as domain (i.e., occupational, transportation, household) and type (e.g., watching television, sitting and playing the piano). It is widely recognized that self-reported PA estimates are often higher than when directly measured (e.g., accelerometer, pedometer, doubly-labeled water, heart rate monitors) $[9,13]$. Previous works have described various measures of SB and their properties [10, 11, 14]. Dall et al. developed a framework (Taxonomy of Self-reported Sedentary behaviour Tools [TASST]) for identifying the optimal self-report tool for population surveillance of SB [14]. Their work found that in the majority of cases, there is a large underestimation of SB from self-report and that composite questionnaires appear to perform better than single questions [14]. To our knowledge there has been no attempt to synthesize the literature to determine how selfreport measures compare to device-assessed measures of SB (criterion validity), nor to assess their reliability in adult populations. Therefore, the primary objective of this systematic review was to compare self-report versus device measures of SB in adult populations. The secondary objective was to assess the reliability of self-report measures.

\section{Methods}

The review was prospectively registered with PROSPERO (\#CRD42019118755).

\section{Study inclusion criteria \\ Population}

Adults with a mean age $\geq 18$ years.

\section{Self-report measures}

Self-report measures may include: diaries or logs (daily reporting of the current/past day's activities possibly in segments of time e.g., between 8:00 am and 10:00 am, 10:01 am to 12:00 pm, etc.); questionnaires (measures designed to collect information about SB either exclusively (e.g., Sedentary Behaviour Questionnaire [SBQ]) or along with other activity intensities (e.g., Global Physical Activity Questionnaire [GPAQ], International Physical Activity Questionnaire [IPAQ]); surveys (self-report measure which may include one or more questions on $\mathrm{SB}$ ); ecological momentary assessments (EMAs; realtime reporting of activities often done with the use of a web- or phone-based app), and, recall interviews (an individual is asked to verbally recall past events). Following 
the TASST framework proposed by Dall et al. [14], selfreport measures may consist of a single item (generates all information about SB using a single question, e.g., total sitting or single behaviour related to $\mathrm{SB}$ ) or be composite (multiple questions about several aspects of SB used to generate a total amount/sum of SB over the same recall period).

\section{Device measures}

Accelerometers (devices that capture "time-varying changes in force" where pre-established cut-points such as $<100$ counts-per-minute are used to classify sedentary time based on energy expenditure [11], e.g., ActiGraph, SenseWear), inclinometers (devices (thigh worn) that capture inclination/postural information used to define sitting, standing and lying $[15,16]$, e.g., activPAL, ActiGraph GT3X+, ActiReg), pedometers (step counters where SB is defined as time spent at less than 100 steps/ minute or with no light activity), heart rate monitors (often combined with accelerometers are able to estimate energy expenditure which can be used to identify sedentary time [17, 18], e.g., ActiGraph ActiTrainer), television monitors (records the amount of time in which a television is turned on - may capture nonsedentary time or time when another person in the household is watching television), car monitors (devices that can record driving activity including driving time [19], e.g. CarChip E/X), and wearable cameras (a camera is worn at chest level and takes regular photos providing a snapshot of activities throughout wear time, they may also be combined with accelerometers [20], e.g., Autographer). Some devices include both an accelerometer and an inclinometer and can capture both movement intensity and postural positions (e.g., activPAL, ActiGraph GT3X+). If a study provided device-assessed SB using output from an accelerometer and an inclinometer, the inclinometer data was chosen by default as it is considered the gold standard for field-based measurement of SB and a more accurate criterion measure [21, 22]. No limitation was placed on the location in which the bodyworn devices were placed (e.g., waist, hip, wrist or arm), but this data was extracted for a sensitivity analysis.

\section{Outcomes}

The primary outcome was minutes per day spent in SB. SB could include total sedentary time, total sitting time, lying time (not sleeping), reading, television/video watching, passive video games, screen time, computer time, passive transportation (e.g., driving/sitting in a car, bus train, plane), etc. Measures needed to be comparable (e.g., self-reported sitting vs. device-assessed sitting or sedentary time). Units were standardized where possible (e.g., conversion of minutes/week to minutes/day). Medians and interquartile range were included by equating the median to the mean and dividing the interquartile range by 1.35 ( $\mathrm{SD}=\mathrm{Q} 3$ - Q1/1.35) [23]. Measures of comparison included correlation coefficients, mean differences and 95\% confidence intervals (CIs), and BlandAltman analyses.

\section{Study designs}

Observational (e.g., cross-sectional, prospective cohort, retrospective cohort) and experimental (e.g., baseline data from randomized controlled trials or quasi-experimental trials) studies that compared the amount of time spent in SB between a self-report and device measure were eligible.

\section{Publication status and language}

Both published (peer-reviewed) and unpublished grey literature (e.g., abstracts) were eligible. No language restrictions were imposed on the search, but only papers published in English or French were included due to translation limitations.

\section{Exclusion criteria}

Studies in which the mean age was $<18$ years, included animals, or which did not compare two measures or in which outcome data from the two measures could not be extracted, and those from which the types of SB were not comparable (e.g., activPAL total sitting vs. selfreported television watching is not comparable whereas self-reported television watching vs. a television monitoring device or wearable camera would be) were excluded from the review.

\section{Search strategy}

The search strategy was created by an information specialist (KF) in discussion with members from the authorship team (SAP, LC, JLR, TJS, JPB). The search was first created in MEDLINE using a combination of index terms/unique subject headings and keywords related to the self-report and device measures and SB. Main concepts searched were "sedentary behaviours", "self-report measures", and "device measures". Only adult and human populations were captured, and a comparison of the two types of measures (self-reported or device) or data to compare the two measures had to be performed for the study to be retained. Once the search was finalized (see Supplemental Table 1 for MEDLINE search strategy), it was translated to the other bibliographic databases.

Searches were conducted from database inception to January 9, 2019 in MEDLINE(R) ALL (Ovid), EMBASE (Embase Classic + Embase, Ovid), PsycINFO (Ovid), CINAHL (EBSCO), SPORTDiscus (EBSCO), and Dissertations \& Theses Global (Proquest). Search results were exported to EndNote X8 (Thompson Reuters, San Francisco, CA, USA) and duplicates removed through 
manual inspection using the EndNote duplicate identification function.

\section{Selection of studies}

Following the initial search, titles and abstracts were exported from EndNote X8 into Covidence (Veritas Health Innovation, Melbourne, Australia) software where further duplicates were removed. Two reviewers independently reviewed all titles and abstracts (SAP, LC, JLR, CK, TJS, JPB) and full texts (SAP, LC, JLR, CK, TJS, JPB). A third reviewer was consulted if disagreements occurred. Reviewers were not blinded to the authors of the studies.

\section{Data extraction and analysis}

Data extraction was completed by one reviewer (SAP) and verified by a second (LC, JLR, CK, TJS, KD, JPB) using standardized data extraction forms in Google Sheets. Information extracted included: publication details; participant characteristics (e.g., age, sex, population), country of study; sample size analyzed (total, male, female); study design; behaviour examined (e.g., sedentary time, sitting time, television time, screen, occupation, passive travel, etc.); self-report measure type (e.g., questionnaire [single or multicomponent], survey, recall interview, diary/log, EMA) and name (e.g., Sedentary Behaviour Questionnaire [SBQ], International Physical Activity Questionnaire [IPAQ]); device measure type (e.g., accelerometer) and name and model (e.g., ActiGraph GT3X, activPAL3); quantity of behaviour within each measure and measure of variance (e.g., minutes and standard deviation $[\mathrm{SD}]$, median and interquartile range); units of measurement (e.g., minutes/day, minutes/week); analytical techniques used to compare measures (e.g., correlation, mean difference, t-test, Bland-Altman); result of comparison (e.g., test statistics); and, reliability assessment details (e.g., time between measures, analytical technique and result).

A narrative synthesis, including summary tables, was used to examine all study results. Forest plots and metaanalyses were created using Review Manager Version 5.3.5 (Copenhagen: The Nordic Cochrane Centre) to compare mean differences (minutes/day) and 95\% CIs in time spent sedentary between self-report and deviceassessed measures. Studies that reported units that could not be converted to minutes per day, that did not provide measures of variance (e.g., SD, 95\% CIs), or did not provide results for comparison were not included in the meta-analyses. If a study reported on weekday, weekend, leisure or occupational-specific time they were included in separate meta-analyses. A minimum of two studies were required to conduct a meta-analysis. Several studies [24-30] included multiple self-report measures compared to one device-assessed outcome (e.g., IPAQ and SBQ compared to activPAL), in this case, the applicable 'arms' were included in the appropriate meta-analysis and the device measure group was split to include half in each comparison as per the Cochrane handbook [23]. If a study reported device-assessed results from both an accelerometer and an inclinometer, the inclinometer data was chosen. A random-effects meta-analysis was used to provide an overall summary measure of effect (mean difference in minutes/day of sedentary time) and 95\% CIs for each meta-analysis. Self-report estimates that on average were within 30 minutes of the device measure were considered to have appropriate agreement. Thirty minutes has been identified as clinically meaningful for having an effect on cardiometabolic health [31-33]. A priori determined subgroup analyses were carried out to test differences for: males vs. females, multi vs. single item questionnaires, week/workday vs. weekend/non-workday recall, work vs. non-work time, questionnaire comparisons (e.g., IPAQ vs. GPAQ vs. SBQ vs. $\log$ vs. diary vs. EMA, etc.), healthy vs. chronic (e.g., diabetes, cardiovascular disease, pulmonary disease, cancer, osteoporosis, arthritis, lupus, fibromyalgia, intellectual disabilities, mental illness, depression, people who are deaf or blind, back pain) populations, and validation against accelerometer vs. inclinometer. If a study only provided sex-stratified results, the individual male and female data were included in the meta-analyses separately, but if a total combined estimate was provided this was used rather than sex-specific estimates (except in the sex-stratified sub-group analysis). Publication bias was conducted using examination of funnel plots for symmetry. Post-hoc sensitivity analyses also examined comparisons in overweight/obese and pregnant populations, by wear location (e.g., hip/waist, wrist, arm, lower back), and accelerometer cut-point.

\section{Risk of bias}

We assessed the quality of the individual studies used in the meta-analyses using a modified version of the QUADAS2 tool used to examine bias in studies of diagnostic accuracy [34]. In the context of this review, the device measure was considered the 'gold standard'. Studies were assessed for potential biases including: selection bias (sampling methods); index test bias [conduct or interpretation of the self-report measure including blinding of device output, continuous vs. categorical measures (continuous being better with an upper threshold), clear definition/question]; reference standard bias (conduct or interpretation of the device measure including the use of validated intensity cutpoints if applicable and interpretation without a selfreport measure), and flow and timing (measures capture the same time period, all participants received same devices). Individual risk of bias information was combined to provide an assessment of overall quality 
of the evidence. Risk of bias assessments were carried out by one assessor (SAP) and verified by a second (LC, JLR, TJS, CK, KD, or JPB).

\section{Results}

\section{Study characteristics}

Figure 1 provides a detailed flow diagram of the literature search and screening process. The preliminary search of the electronic databases identified 4,464 potentially relevant papers. Of these, 1,089 were identified in MEDLINE, 1,313 in EMBASE, 271 in PsycINFO, 266 in SPORTDiscus, 1,240 in CINAHL, and 285 in Dissertations and Theses Global. After de-duplication, 2,881 relevant papers remained. A preliminary title and abstract review resulted in the retrieval of 591 full text papers for a detailed assessment. Author's knowledge and bibliographies identified a further three papers. Of these, 185 unique studies met the criteria for study inclusion [19, 20, 24-30, 35-210]. Individual study characteristics can be seen in Supplemental table 2 . Common reasons for excluding studies included: no measure of SB ( $\mathrm{n}=114)$; no comparisons of measures $(\mathrm{n}=80)$; not adult population $(\mathrm{n}=5)$; no self-report measure $(\mathrm{n}=66)$; no device measure $(\mathrm{n}=46)$; measures not comparable $(\mathrm{n}=23)$; no measure of variance $(\mathrm{n}=$ $6)$; duplicate study $(\mathrm{n}=31)$; review paper $(\mathrm{n}=15)$; not English or French $(\mathrm{n}=14)$; study protocol with no results $(\mathrm{n}=6)$; and, unable to obtain full text $(\mathrm{n}=3)$.

The included studies were published from 2004 to 2019; the majority from the past five years. A total of 36 countries were represented by at least one study. The countries with the most studies included the United States (29\%) and Australia (15\%). A greater number of studies reported on female-specific data/populations compared to maleonly data. The IPAQ-SF (37 studies), IPAQ-LF (32 studies), GPAQ (17 studies), SBQ (13 studies), and the Occupational Sitting and Physical Activity Questionnaire (OSPAQ; 8 studies) were the most common self-report measures and the ActiGraph GT3X the most used device measure followed by the activPAL. All but six of the studies $[42,91,101,102,122,205]$ that employed inclinometers used activPALs. Accelerometers were largely worn on the hip (some reported wear at the wrist, arm or thigh) whereas inclinometers were worn exclusively on the thigh.
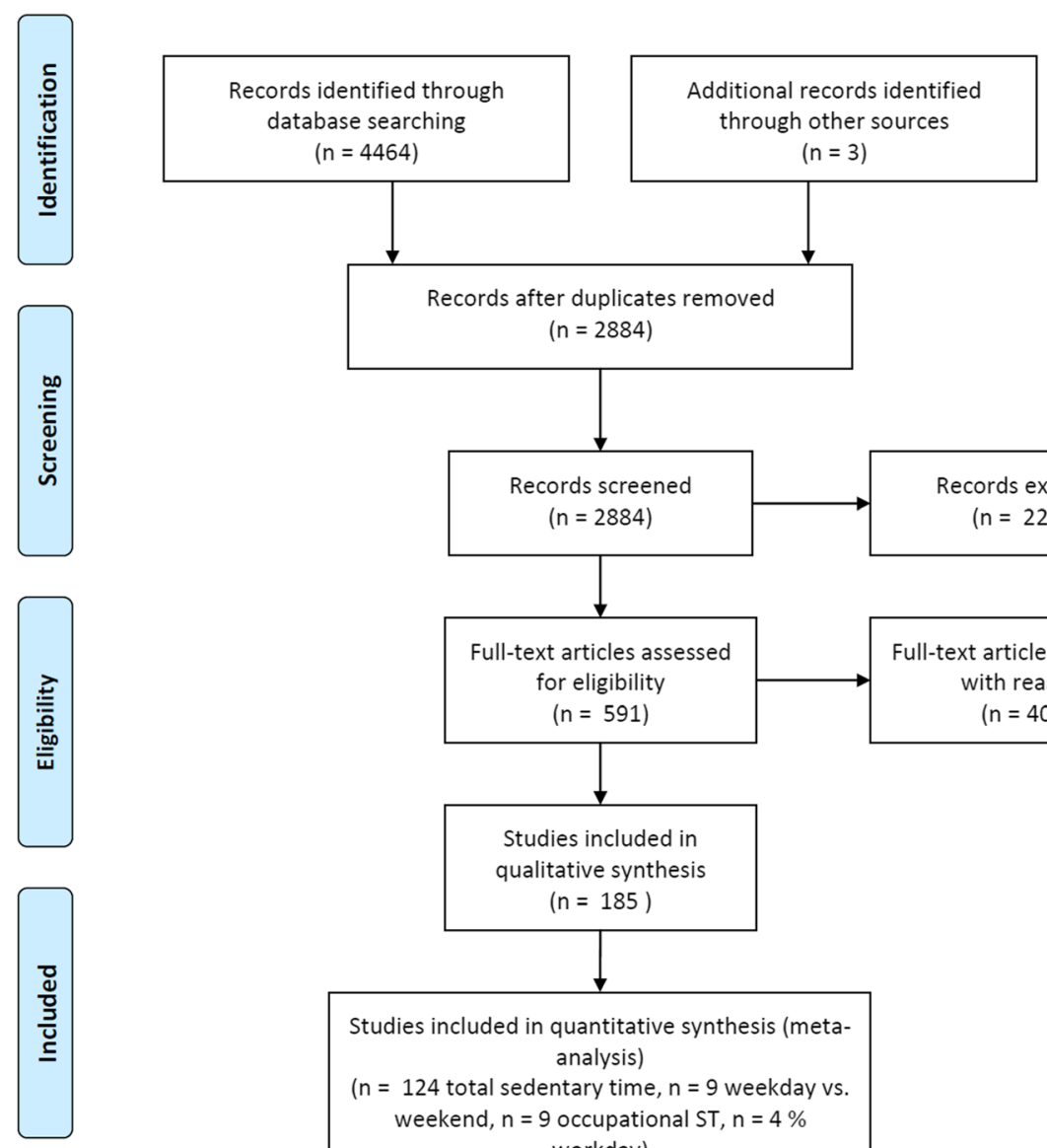

cords after duplicates removed $(n=2884)$

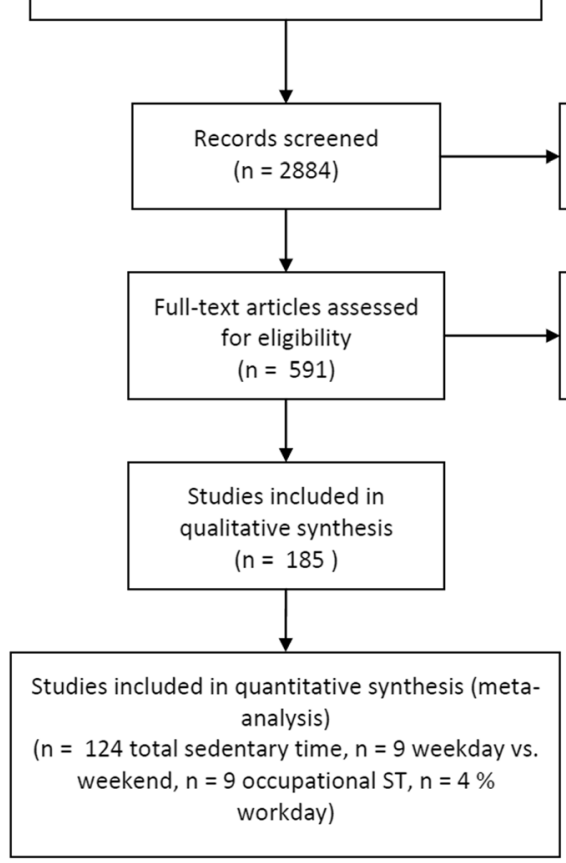

Fig. 1 PRISMA flow diagram 
Devices used to objectively measure sedentary time included: accelerometers, inclinometers, combined camera + accelerometers, combined heart rate + activity monitors, television monitors, and car monitors.

\section{Risk of bias}

Risk of bias results are summarized in Fig. 2, individual study risk of bias results can be seen in the respective forest plots. Seventy-five percent of the studies had a high risk of selection bias largely due to the use of convenience samples or including populations that were specialized (thereby limiting the generalizability of their findings to the general population). The majority (80\%) of studies had a low risk of bias related to the reference standard (device) as most used validated thresholds to define SB or used inclinometry. Approximately 50\% had inadequate information to assess the quality of the index test as most failed to mention whether an upper threshold was instituted on continuous reporting outcomes, while approximately $30 \%$ had a low risk of bias related to the self-report measure. While the majority (60\%) of studies had a low risk of bias related to the flow and timing of measures, $\sim 20 \%$ had a mismatch between the time period of data collection by the self-report and device measures. In the conduct of this review, flow and timing was considered the most critical form of bias. There was, however, no clear trend in the degree of agreement between the two measures based on this bias.

\section{Validity}

Supplemental table 3 provides study findings for all studies comparing a self-report and device measure of SB. A total of 147 studies reported a correlation coefficient between a self-report and device measure of sedentary time. Supplemental figure 1 is a plot of all the extracted correlations and shows, that on average, the correlations between self-report and device measures was low-to-moderate at $\mathrm{r}=0.32(\mathrm{SD}=0.21)$ and ranged from -0.19 to 0.87 . Negative correlations would imply that as self-report values are higher while device-based measures are lower.

A total of 123 studies comprising 173 comparisons and data from 55,199 participants were used to examine the criterion validity of self-reported average sedentary or sitting time by comparison to a device measure of sitting or sedentary time [24-30, 35-40, 42, 43, 47, 48, 5056, 58, 62-64, 66-68, 73, 74, 76-82, 84-86, 88-90, 92, 94-100, 102-104, 107-109, 111-113, 116, 117, 120, 121, 124-126, 128, 129, 131-133, 135, 138-140, 142-145, $147,148,151,153,156,157,160,161,163-165,168$, $170,171,173-177,180,182-184,186-189$, 191, 194196, 198-200, 202, 203, 206, 208-210]. The average mean difference (MD) between measures was -105.19 minutes/day (95\% CI: -127.21, -83.17) indicating that self-report tools underestimated sedentary time by approximately 1.74 hours/day compared to device measures (Supplemental figure 2). Heterogeneity was high $\left(\mathrm{I}^{2}=99 \%\right)$ indicating a great deal of variation between studies with as much as 6 hours/day discrepancy within individual studies. There was no clear pattern in underor over-reporting based on the risk of bias associated with timing and flow. The funnel plot was largely symmetrical and there was no apparent publication bias.

Additional studies examined and compared the criterion validity of self-report measures under the following conditions: nine studies (19 comparisons) on weekday/ workday (includes time at work and outside of work) vs. weekend/non-workday sedentary time $[24,47,51,58$, $69,70,86,156,198]$; 2 studies (5 comparisons) on minutes per day of self-reported television time [141, 155]; nine studies (11 comparisons) on minutes per day of occupational sedentary time $[61,65,75,99,101,105,122$, 136, 181, 188, 193]; and, four studies (five comparisons) on the proportion of a workday spent sedentary [91, $105,158,205]$. In all of these studies a comparable criterion was required (e.g., self-reported occupational sitting was compared to accelerometer sedentary time during work time only). Self-reported weekday/workday $\left(\mathrm{MD}=-77.60,95 \% \mathrm{CI}:-121.36,-33.84, \mathrm{I}^{2}=93 \%\right)$ and

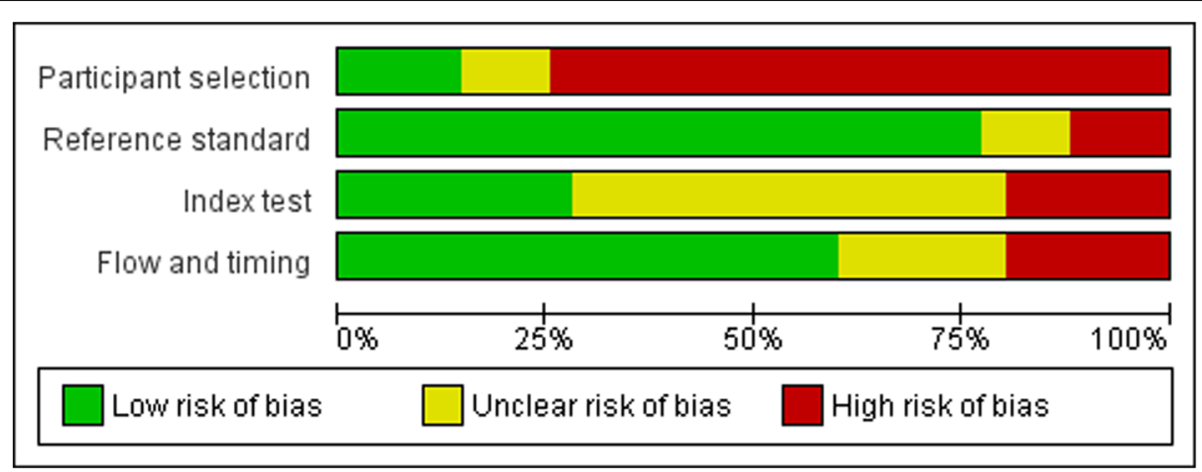

Fig. 2 Summary risk of bias graph 
weekend/non-workday $(\mathrm{MD}=-87.92,95 \%$ CI: -149.15 , $\left.-26.69, \mathrm{I}^{2}=95 \%\right)$ sedentary time were both significantly different than device-assessed sedentary time, but were not significantly different from each other (Supplemental figure $\left.3, x^{2}=0.07, d f=1, p=0.79\right)$. Self-reported television time was significantly lower than television time derived from a combination of logs and accelerometers or television monitoring devices (Supplemental figure 4, $\mathrm{MD}=-31.82$ minutes/day, 95\% CI: $-49.36,-14.29$, $\left.\mathrm{I}^{2}=0 \%\right)$. On average, self-reported time spent sedentary at work was significantly greater than that assessed by device (regardless of device) (Supplemental figure $5, \mathrm{MD}=+37.81$ minutes/day, $95 \%$ CI: $22.41,53.21$, $\left.\mathrm{I}^{2}=50 \%\right)$. Self-reported proportion of a workday spent sedentary was not significantly different from the inclinometer-assessed proportion (Supplemental figure 6, $\left.\mathrm{MD}=+2.25 \%, 95 \% \mathrm{CI}:-2.42 \%, 6.93 \%, \mathrm{I}^{2}=66 \%\right)$.

Subgroup analyses found that males $(\mathrm{MD}=-130.38$, 95\% CI: $\left.-182.34,-78.41, \mathrm{I}^{2}=98 \%\right)$ and females (MD = $-143.75,95 \%$ CI: $\left.-189.93,-97.57, \mathrm{I}^{2}=99 \%\right)$ underreported their sedentary time by a similar amount when compared to device measures (Supplemental figure 7, $x^{2}$ $=0.14, \mathrm{df}=1, \mathrm{p}=0.71)$. Examining only those studies which provided both male- and female-specific data did not change the findings $\left(x^{2}=0.01, d f=1, p=0.91\right)$.

No significant between group differences in the discrepancy between self-report and device measures were observed for participants from apparently healthy populations, chronic populations, pregnant women or those who were considered overweight or obese (Supplemental figure $\left.8, x^{2}=3.18, \mathrm{df}=3, \mathrm{p}=0.36, \mathrm{I}^{2}=5.6 \%\right)$. Those from apparently healthy populations (MD $=-89.96,95 \%$ CI: $-114.45,-65.46, \mathrm{I}^{2}=99 \%$ ), chronic populations (MD $=-154.01,95 \%$ CI: $\left.-223.98,-84.04, \mathrm{I}^{2}=99 \%\right)$, and those who were considered overweight or obese (MD = $-104.59,95 \%$ CI: $-197.97,-11.20, \mathrm{I}^{2}=99 \%$ ) all underreported their sedentary time compared to the device measure. Among the three studies that included pregnant women, self-reports were not significantly different than device measures, though they trended toward under-reporting (MD = -74.16, 95\% CI: $-156.09,7.77, \mathrm{I}^{2}=$ $90 \%)$. Chronic populations appear to under-report to a greater degree than apparently healthy populations $\left(\mathrm{x}^{2}=\right.$ $2.87, \mathrm{df}=1, \mathrm{p}=0.09, \mathrm{I}^{2}=65.1 \%$ ).

Subgroup comparisons were used to test the performance of single sedentary questions (e.g., IPAQ-LF [only sitting questions], IPAQ-SF, GPAQ) compared to multiitem/component questionnaires (excluding IPAQ + motorized travel), EMAs, and logs/diaries. A significant between group difference was found (Fig. $3, x^{2}=36.51$, df $\left.=3, \mathrm{p}<.00001, \mathrm{I}^{2}=91.8 \%\right)$ whereby single item measures, on average, significantly under-reported sedentary time compared to device measures $(\mathrm{MD}=-159.56,95 \% \mathrm{CI}$ : $\left.-189.69,-129.44, \quad I^{2}=99 \%\right)$, whereas multi-item



Fig. 3 Summary forest plot comparing self-report and device measures of total sedentary or sitting time between single vs. multiitem vs. EMAs vs. diaries/logs, minutes/day

questionnaires $\left(\mathrm{MD}=-10.93,95 \% \mathrm{CI}:-51.13,29.28, \mathrm{I}^{2}=\right.$ 99\%), EMAs (MD $=-51.56,95 \% \mathrm{CI}:-252.33,149.21, \mathrm{I}^{2}=$ 98\%) and $\log /$ diaries $(\mathrm{MD}=-49.10,95 \% \mathrm{CI}:-113.08$, $\left.14.88, \mathrm{I}^{2}=92 \%\right)$ did not. Almost all $(82 \%)$ of the single item studies significantly under-reported compared to $37 \%$ of multi-item questionnaires and $22 \%$ of logs/diaries. A sub-group analysis was also performed to examine the effect of recall duration on self-report measure performance. Current day (MD $=-36.14,95 \% \mathrm{CI}:-88.30,16.02)$ and previous day $(-5.22,95 \% \mathrm{CI}:-68.76,58.31)$ recalls performed the best, while recalls over the previous seven days $(\mathrm{MD}=-134.39,95 \% \mathrm{CI}:-161.14,-107.64)$, previous month $(\mathrm{MD}=-204.04,95 \% \mathrm{CI}:-241.64,-166.43)$, usual day (MD $=-112.49,95 \%$ CI: $-171.09,-53.89)$, and usual week (MD $=-121.01,95 \%$ CI: $-303.36,61.34)$ performed the worst (Fig. 4, Supplemental figure 9). Almost all previous week recalls underestimated sedentary time, while previous day was more evenly split between under- and overestimation and current day had the smallest mean differences within the individual studies.

Within questionnaires there was a significant between group difference (Supplemental figure 10, $\chi^{2}=121.98, \mathrm{df}$ $\left.=12, \mathrm{p}<0.00001, \mathrm{I}^{2}=90.2 \%\right)$. The IPAQ-Short Form $\left(\mathrm{MD}=-161.67,95 \% \mathrm{CI}:-226.38,-96.95, \mathrm{I}^{2}=99 \%\right)$, IPAQ-Long Form sitting questions (MD $=-150.76$, 95\% CI: -193.68, -107.83, $\left.\mathrm{I}^{2}=99 \%\right)$, IPAQ-Long Form sitting + motorized travel $\left(\mathrm{MD}=-271.67\left(-397.68,-145.36, \mathrm{I}^{2}=\right.\right.$ 99\%), and GPAQ (MD $=-219.85,95 \%$ CI: -288.68 , $-151.02, \mathrm{I}^{2}=98 \%$ ) had the greatest discrepancy between self-reported sitting time and device-assessed sedentary time. The SBQ performed the best with an average mean difference of $\sim 6$ minutes/day $(\mathrm{MD}=-5.80,95 \% \mathrm{CI}$ : $\left.-73.48,61.87, \mathrm{I}^{2}=97 \%\right)$. However, the SBQ studies had a high level of heterogeneity and were split with 4/9 significantly under-reporting and 3/9 significantly overreporting, whereas the IPAQ and GPAQ consistently under-reported sitting time. On average, the Multimedia Activity Recall for Children and Adolescents (MARCA) 


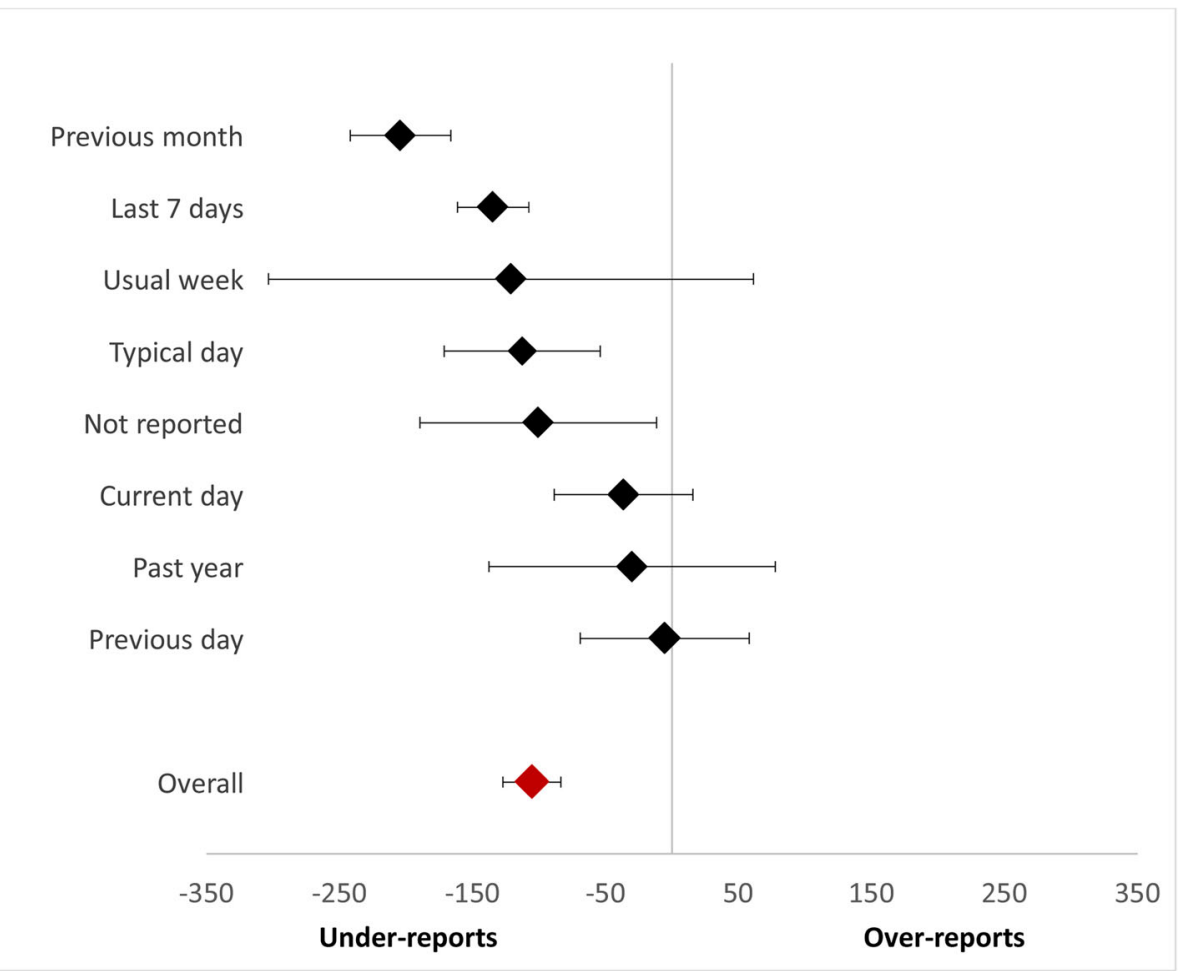

Fig. 4 Summary forest plot comparing self-report and device measures of total sedentary time or sitting time across self-report recall periods

questionnaire $\left(\mathrm{MD}=56.56,95 \% \mathrm{CI}: 22.61,90.52, \mathrm{I}^{2}=\right.$ $13 \%)$ and the sitting time questionnaire developed by Marshall [134] (MD = 83.85, 95\% CI: $-1.00,168.71, \mathrm{I}^{2}=$ $89 \%)$ over-reported sedentary time compared to device measures.

A sub-group analysis identified that the difference between self-report and device measures varied depending on the type of device used (Supplemental figure 11, $\mathrm{X}^{2}=$ $\left.25.99, \mathrm{df}=2, \mathrm{p}<0.00001, \mathrm{I}^{2}=92.3 \%\right)$. A significant difference between accelerometer $(\mathrm{MD}=-125.48,95 \% \mathrm{CI}$ : $\left.-151.58,-99.39, \mathrm{I}^{2}=99 \%\right)$ and a combined accelerometer + heart rate monitor $(\mathrm{MD}=-157.68,95 \% \mathrm{CI}:-209.35$, $\left.-106.01, \mathrm{I}^{2}=97 \%\right)$ and self-report measures was observed. An analysis of different models of accelerometers (i.e., ActiGraph 7164, ActiGraph GT1M, ActiGraph GT3X, SenseWear) revealed no between group differences $\left(\chi^{2}=\right.$ $\left.3.64, \mathrm{df}=3, \mathrm{p}=0.30, \mathrm{I}^{2}=17.6 \%\right)$. Further, when comparing accelerometer cut-points (e.g., $50 \mathrm{cpm}$ x-axis, $100 \mathrm{cpm}$ $\mathrm{x}$-axis, $100 \mathrm{cpm}$ vector magnitude, $150 \mathrm{cpm}$ vector magnitude) against a single-item measure (e.g., IPAQ, GPAQ) there were no between group differences (Supplemental figure $12, \mathrm{x}^{2}=5.23$, $\left.\mathrm{df}=3, \mathrm{p}=0.16, \mathrm{I}^{2}=42.7 \%\right)$. The majority of accelerometers with wear location reported were worn on the dominant hip or waist. A sensitivity analysis of wear location found that the self-report measures were significantly lower when compared to wrist vs. waist/hip locations (Supplemental figure 13, $x^{2}$ $\left.=21.35, \mathrm{df}=3, \mathrm{p}<0.00001, \mathrm{I}^{2}=85.9 \%\right)$. On average, self-report measures when compared to monitors worn on the upper arm (e.g. SenseWear Armband) were not significantly different $(\mathrm{MD}=-81.74,95 \% \mathrm{CI}:-174.53$, $\left.11.04, \mathrm{I}^{2}=99 \%\right)$, though there was a high degree of variation between and within studies (up to almost 4 hours/day), and most self-report measures were multicomponent or diaries/logs. Contrary to the accelerometer results, no significant differences were observed when comparing self-report measures to an inclinometer $\left(\mathrm{MD}=-10.55,95 \% \mathrm{CI}:-52.30,31.19, \mathrm{I}^{2}=98 \%\right)$. However, when only studies that included both an accelerometer and inclinometer (e.g., Actigraph + activPAL) outcome compared to a self-report measure were used, no significant difference between the self-report and device measure were observed $\left(\mathrm{x}^{2}=0.30, \mathrm{df}=1, \mathrm{p}=0.58, \mathrm{I}^{2}=\right.$ $0 \%)$ when comparing activPAL $(\mathrm{MD}=6.86,95 \% \mathrm{CI}$ : $-46.78,60.49$ ) and accelerometers (MD $=-13.06,95 \% \mathrm{CI}$ : $-60.26,34.15)$. A sensitivity analysis found that selfreported sedentary time using single-item questionnaires (including IPAQ-LF without motorized transport) was significantly lower when compared to both inclinometers $(\mathrm{MD}=-127.29,95 \% \mathrm{CI}:-213.85,-40.72)$ and accelerometers $(\mathrm{MD}=-156.84,95 \% \mathrm{CI}:-190.04,-123.64)\left(\chi^{2}=0.39\right.$, $\left.\mathrm{df}=1, \mathrm{p}=0.53, \mathrm{I}^{2}=0 \%\right)$. However, when multi-item questionnaires (including IPAQ-LF + motorized transport), logs/diaries and EMAs were compared to device 
measures, they performed better when compared to inclinometers $(\mathrm{MD}=22.59,95 \% \mathrm{CI}:-23.18,68.35)$ versus accelerometers $(\mathrm{MD}=-62.18,95 \% \mathrm{CI}:-105.77,-18.59)\left(\chi^{2}=\right.$ 6.91, $\left.\mathrm{df}=1, \mathrm{p}=0.009, \mathrm{I}^{2}=85.5 \%\right)$.

\section{Reliability}

A total of 54 studies provided an assessment of reliability of a self-report measure (Supplemental table 4). The intraclass correlation coefficient (ICC) was the most reported reliability statistic (46 studies) and is a measure of test-retest reliability used to assess whether similar estimates of the outcome (i.e., SB) were obtained across multiple assessments. ICC values range from 0 to 1 ; where 1 indicates perfect reliability and 0 represents a lack of reliability. In this review we considered an ICC over 0.75 to be excellent, between 0.60 and 0.74 to be good, between 0.40 and 0.59 to be fair, and $<0.40$ to be poor [211]. Figure 5 is a plot of all the extracted ICCs and shows that on average, the reliability of the selfreport measures was good with $\mathrm{ICC}=0.66(\mathrm{SD}=0.22)$ and ranged from -0.13 to 0.91 .

\section{Discussion}

To our knowledge, this review represents the most comprehensive comparison to date of self-report and deviceassessed SB measures in adults. Contrary to what was previously found in the PA literature $[9,13]$, the majority of the studies included in this review reported on units that were comparable between the two measures and reported measures of variance around estimates. This allowed us to conduct large meta-analyses to compare self-report and device measures and to perform a series of sub-group analyses.
On average, we found that self-report measures underreported sedentary/sitting time when compared to device measures by 1.74 hours/day (95\% CI: $-2.11,-1.38$ hours/day) with $72 \%$ of comparisons identifying that self-reports under-reported compared to device measures. Single question measures (e.g., IPAQ, GPAQ) resulted in significant under-reporting of sedentary time compared to all device measures, whereas multi-item questionnaires, EMAs, and logs/diaries did not, and performed relatively well, especially when compared to activPALs (the gold standard of field-based sitting). Therefore, it appears that the use of multi-item questionnaires, logs/diaries and EMAs may provide more comparable results to device measures versus singleitem questions. There was, however, a large and significant degree of variability within (up to 4.5 hours/day) and between studies, and this was present in most of the meta-analyses performed. In the case of diaries/logs and EMAs where fewer studies were used in the metaanalysis, this variability further limits our confidence in the reproducibility of the results. While most led to an under-reporting (though to different degrees), some provided similar estimates and some over-reported and the 95\% CIs around these estimates were often quite large with the majority greater than 30 minutes. This variability has great consequences for the interpretation and use of measures and is something that users should consider when deciding on which tool to use. For example, while multi-item questionnaires, EMAs and logs/diaries had more acceptable mean differences, the variability was quite large and not generally acceptable (up to 1.8 hours/day). It is also important to recognize that most studies that employed a single item did so using the global sitting question from the IPAQ or the

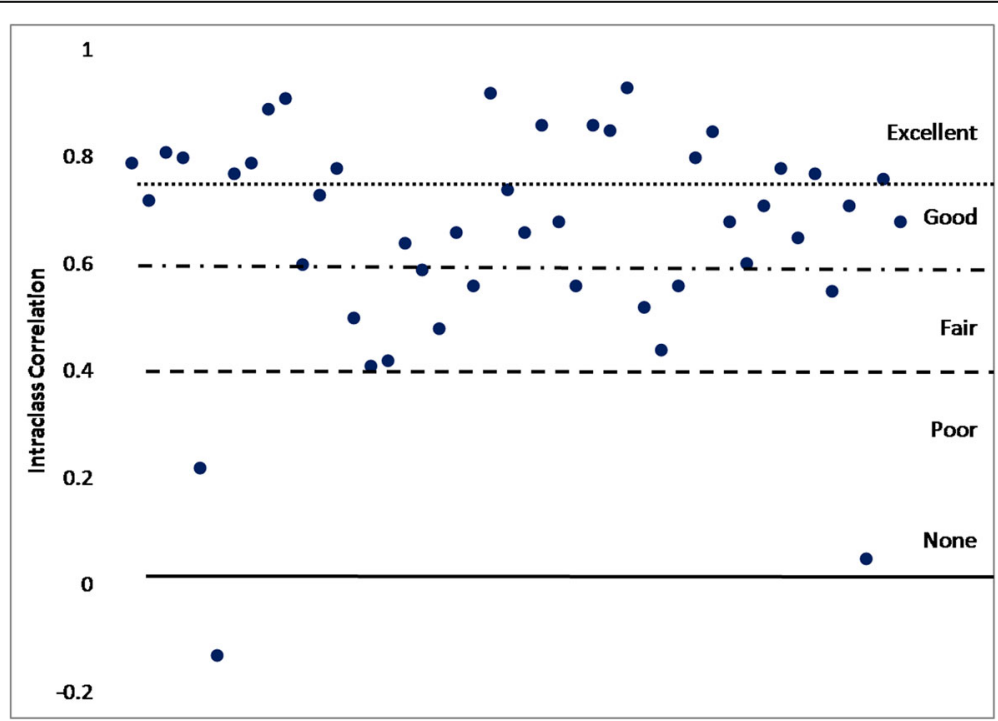

Fig. 5 Intraclass correlation coefficients between repeated self-report measures 
GPAQ (or based on these questions). The sitting time question is part of a larger questionnaire on PA and was developed for surveillance purposes, whereas multiitem SB questionnaires such as the SBQ and WSQ were designed as standalone surveys to obtain more detailed estimates of SB.

Self-reported work-time spent sedentary appeared to be better recalled compared to total day sedentary time. Interestingly, questionnaires that asked participants to recall the proportion of their workday spent sedentary did not significantly differ from inclinometer-assessed sedentary time ranging from an average over-reporting of $9 \%$ to under-reporting by $4 \%$. Chastin et al., compared 18 self-report measures of sedentary time against an activPAL and found tools that used a scale to assess the proportion of daily time spent sitting had the lowest amount of missing data and best agreement with deviceassessed measures [25]. Matsuo et al. also found that when Japanese workers were asked to indicate the percentage of time spent sitting at work it improved the reliability and validity of the Workers' Sitting and Walking-time Questionnaire (WSWQ) compared to asking them to recall length of time [136]. Asking individuals to recall the proportion of their day spent sitting rather than recalling absolute time appears to provide more accurate measures of sitting especially in the context of workplace sitting. Future studies would benefit from assessing this method using a total-day approach.

It is important to remember that self-report and device measures provide different and complimentary information $[10,212]$. As described by Colley et al. (2018), self-report measures provide a measure of the behaviour as perceived and thereby estimated by the respondent and can provide more contextual information such as the type of SB being performed (e.g., television watching, passive transport, screen time) whereas device measures continuously capture bodily movement at specific thresholds [213] or in the case of inclinometers time spent in specific postures (i.e. sitting/ lying), but often lack contextual information except in the case of wearable cameras or user monitor devices (e.g., television, computer and car use monitors).

EMAs, logs/diaries and previous day recalls generally performed better than single item questionnaires which ask participants to recall total sitting in the past week/month/year or on a usual day as they remove or attenuate potential recall and response biases by capturing self-report closer to 'real-time' and often assess details about body position and different types of behaviours. They also provide an upper threshold for reporting by asking respondents to reflect upon smaller portions of time. Similarly to what was observed by Chastin et al., multi-item questionnaires performed better than single-item questions for accuracy, but with both having poor precision (large 95\%
CIs) [25]. This may be attributed to asking respondents to recall specific sedentary activities/behaviours (i.e., television watching, time spent commuting) thereby providing cues to recall behaviours which may not be otherwise considered or which may occur over smaller periods of time rather than estimating how much time one spends sitting throughout a day. Self-reported occupational sedentary time also tended to be over-reported, but performed better than total sitting measures. It may be easier for respondents to recall time spent sitting at work or during a task than recalling time over the course of the day.

Contrary to what has been observed in the literature for PA [9], there does not appear to be gender differences in how men and women report their sedentary time compared to device measures. Further, findings were similar between general/apparently healthy and chronic (e.g., presence of disease or condition) populations improving the generalizability of the results. Interestingly, Chastin et al. [25] compared 18 different combinations of selfreport measures in the same population and identified large differences in the performance of the measures. This evidence also supports that differences between studies are not necessarily attributed to differences in populations. Findings were, however, different depending on the device used for comparisons. Comparisons made with accelerometers or combined accelerometer + heart rate monitors showed lower accuracy compared to inclinometers (e.g., activPALs), but all had a great degree of variability within and between studies (up to 6 hours/day compared to accelerometers and up to 4.6 hours/day compared to inclinometers). This was especially true when looking at differences in multi-item questionnaires, EMAs and logs/diaries. Inclinometers (especially activPALs) are considered a "gold standard for the objective measurement of sedentary/sitting time" [25] and are recommended for assessing SB in the field [22]. Inclinometers assess time spent in specific postures (i.e., sitting/lying) by using acceleration to measure the inclination of the thigh (thigh wear is the most valid for posture) relative to gravity, the combination of movement intensity and posture align with the definition of SB [3]. Accelerometers generally apply a movement threshold (most notably $<100 \mathrm{cpm}$ ) to define time spent sedentary. It is therefore, possible that these thresholds identify other behaviours (i.e. standing stationary) that would not be considered sedentary activities and may explain the greater discordance between self-report and accelerometer measures. Further, although our comparison of accelerometer cutpoints against single-item questions showed no significant differences, different thresholds have been shown to capture different amounts of SB [22, 214] with the potential to affect the comparability between measures.

Research has shown that self-report and device-based measures of SB associate differently with health outcomes 
[53, 163, 215, 216]; device-assessed SB has been shown to associate more strongly with mortality compared to selfreported sitting [216, 217]. It also appears that health risks associate differently or have a stronger relationship with different types and domains of self-reported SB [4, 218]. For example, greater self-reported television has been shown to be more strongly associated with mortality than self-reported total sitting [4]. This may be due in part to television's association with unhealthy food and beverage consumption and sleep $[219,220]$ or to our ability to more accurately recall this specific behaviour, but future work is needed to better understand why different types of SB and why self-report and device measures associate differently with health outcomes.

Although correlation between self-report and device measures was low-to-moderate, self-report measures had an acceptable level of reliability. Reliability is important when assessing SB over time whether to assess changes from an intervention or to monitor prevalence in a population [10].

\section{Limitations}

This review has limitations that should be considered when extrapolating results. First, the review was limited to studies that included directly comparable SB data between the self-report and device measures. This greatly reduced the number of studies examining self-reported activities such as television and passive transit which are difficult to compare to device measures of the same behaviour. However, it does provide an assessment of questionnaires that included multiple SBs and many that examine self-reported sitting. It should be noted that almost all the meta-analyses demonstrated a high degree of heterogeneity between and within (up to 6 hours/day) studies, limiting our confidence in the estimates. However, given the large number of included studies, we feel that the high degree of heterogeneity is likely, at least in part, explained by the potential variability in recall and response bias within study populations. While we did not identify any difference in healthy vs. chronic populations, there may be other respondent-level factors at play. Within studies that assessed television viewing, we cannot be certain that individuals were undertaking non-sedentary behaviours while the television was on.

\section{Conclusions}

This review presents a comprehensive examination of self-report measures of SB and how they compare to device measures. The field of SB has experienced a rapid rate in growth over the last 5-10 years and with this growth has come an evolution of measurement methods. While devices have become increasingly used for assessing these behaviours, they provide limited contextual information to explain where and how individuals are sedentary. Self-report measures continue to be the most widely used methods to assess these behaviours. Evidence from this review suggests that selfreport single-item measures generally underestimate sedentary time when compared to device measures. Multi-items questionnaires, EMAs and logs/diaries and tools that employ a shorter recall period perform well with respect to accuracy, especially when compared to inclinometers, but present with a high degree of variability (many over- and under- reporting) within and between studies leading to poor precision. This variability, which in individual studies could be as much as six hours/day, has great consequences for the interpretation and use of measures. It is apparent that there is an abundance of self-report tools available for researchers, making it difficult to compare findings across studies. Researchers should exert caution when comparing associations between different self-report and device measures with health outcomes.

\section{Supplementary information}

Supplementary information accompanies this paper at https://doi.org/10. 1186/s12966-020-00938-3

\section{Additional file 1: Supplemental figure 1. Correlation coefficients} between self-report and device measures.

Additional file 2: Supplemental figure 2. Forest plot comparing self841 report and device measures of total sedentary or sitting time, minutes/ day.

Additional file 3: Supplemental figure 3. Forest plot comparing self843 report and device measures of total sedentary or sitting time between 844 weekday/work days and weekend/non-work days, minutes/ day

Additional file 4: Supplemental figure 4. Forest plot comparing self846 report and device measures of television viewing time, minutes/day.

Additional file 5: Supplemental figure 5. Forest plot comparing self-report and device measures of total occupational sedentary time, minutes/day.

Additional file 6: Supplemental figure 6. Forest plot comparing selfreport and device measures of workday spent sedentary, \% of day.

Additional file 7: Supplemental figure 7. Forest plot comparing selfreport and device measures of total sedentary or sitting time between men and women, minutes/day.

Additional file 8: Supplemental figure 9. Forest plot comparing selfreport and device measures of total sedentary or sitting time between recall periods, minutes/day.

Additional file 9: Supplemental figure 8. Forest plot comparing selfreport and device measures of total sedentary or sitting time between population subgroups, minutes/day.

Additional file 10: Supplemental figure 10. Forest plot comparing self-report and device measures of total sedentary or sitting time across questionnaires, minutes/day.

Additional file 11: Supplemental figure 11. Forest plot comparing self-report and device measures of total sedentary or sitting time between devices, minutes/day.

Additional file 12: Supplemental figure 12. Forest plot comparing self-report and accelerometer measures of total sedentary or sitting time across cut-points, minutes/day. 
Additional file 13: Supplemental figure 13. Forest plot comparing self-report and device measures of total sedentary or sitting time across wear locations, minutes/day.

Additional file 14: Supplemental table 1. Ovid MEDLINE search strategy.

Additional file 15: Supplemental table 2. Study characteristics. Additional file 16: Supplemental table 3. Validity characteristics. Additional file 17: Supplemental table 4. Reliability characteristics.

\section{Acknowledgements}

The authors would like to acknowledge our peer reviewers who raised some excellent points for analysis and discussion. This paper has been strengthened as a result of their feedback.

\section{Authors' contributions}

SAP, LC, JLR and JPB conceived the study, SAP, LC, JLR, TJS, KF, and JPB designed the study, SAP, LC, JLR, CK, KD, TJS, and JPB screened the studies, all authors participated in data extraction. SAP performed the meta-analyses and led the writing of the paper. All authors edited and critically reviewed the manuscript. SAP had the primary responsibility for the final manuscript. All authors read and approved the final manuscript.

\section{Funding}

Dr. Stephanie Prince was funded by a Canadian Institutes of Health Research (CIHR) - Public Health Agency of Canada Health System Impact Fellowship. Dr. Jennifer Reed is funded, in part, by a CIHR New Investigator Salary Award. Dr. Jennifer Reed was awarded a Planning and Dissemination Grant (\#150435) from the CIHR to support Open Access publication charges.

\section{Availability of data and materials}

All data generated or analysed during this study are included in this published article [and its additional files].

\section{Ethics approval and consent to participate}

Not applicable.

\section{Consent for publication}

Not applicable.

\section{Competing interests}

The authors declare that they have no competing interests.

\section{Author details}

'Division of Cardiac Prevention and Rehabilitation, University of Ottawa Heart Institute, Ottawa, Canada. ${ }^{2}$ Centre for Surveillance and Applied Research, Public Health Agency of Canada, 785 Carling Avenue, Ottawa K1A 0K9, Canada. ${ }^{3}$ Birmingham Community Healthcare NHS Foundation Trust, Community Cardiac Services, Birmingham, United Kingdom. ${ }^{4}$ Centre for Active Living, University Centre Shrewsbury, University of Chester, Guildhall, Frankwell Quay, Shrewsbury, United Kingdom. ${ }^{5}$ School of Human Kinetics, Faculty of Health Sciences, University of Ottawa, Ottawa, Canada. ${ }^{6}$ School of Epidemiology and Public Health, Faculty of Medicine, University of Ottawa, Ottawa, Canada. ${ }^{7}$ Department of Applied Human Sciences, University of Prince Edward Island, Charlottetown, Canada. ${ }^{8}$ School of Life and Health Sciences, Aston University, Birmingham, United Kingdom. ${ }^{9}$ Health Sciences Library, University of Ottawa, Ottawa, Canada.

\section{Received: 17 October 2019 Accepted: 19 February 2020}

Published online: 04 March 2020

\section{References}

1. Biswas A, Oh PI, Faulkner GE, Bajaj RR, Silver MA, Mitchell MS, et al. Sedentary time and its association with risk for disease incidence, mortality, and hospitalization in adults: a systematic review and meta-analysis. Ann Intern Med. 2015;162(2):123-32.

2. LeBlanc AG, Gunnell KE, Prince SA, Saunders TJ, Barnes JD, Chaput J-P. The ubiquity of the screen: an overview of the risks and benefits of screen time in our modern world. Transl J Am Coll Sports Med. 2017;2(17):104-13.
3. Tremblay MS, Aubert S, Barnes JD, Saunders TJ, Carson V, Latimer-Cheung $A E$, et al. Sedentary behavior research network (SBRN)-terminology consensus project process and outcome. Int J Behav Nutr Phys Act. 2017; 14(1):75.

4. Ekelund U, Steene-Johannessen J, Brown WJ, Fagerland MW, Owen N, Powell KE, et al. Does physical activity attenuate, or even eliminate, the detrimental association of sitting time with mortality? A harmonised metaanalysis of data from more than 1 million men and women. Lancet. 2016; 388(10051):1302-10.

5. World Health Organization. Recommended levels of physical activity for adults aged 18 - 64 years 2011 [Available from: https://www.who.int/ dietphysicalactivity/factsheet_adults/en/.

6. Public Health Agency of Canada. Sedentary Behaviour and Sleep (PASS) Indicators, Quick Stats, Adults (18+ years), 2018 Edition. 2018. [Available from: https://health-infobase.canada.ca/pass/.

7. Du Y, Liu B, Sun Y, Snetselaar LG, Wallace RB, Bao W. Trends in Adherence to the Physical Activity Guidelines for Americans for Aerobic Activity and Time Spent on Sedentary Behavior Among US Adults, 2007 to 2016. JAMA Network Open. 2019;2(7):e197597-e.

8. Loyen A, Clarke-Cornwell AM, Anderssen SA, Hagströmer M, Sardinha LB, Sundquist $K$, et al. Sedentary time and physical activity surveillance through accelerometer pooling in four European countries. Sports Med. 2017;47(7): 1421-35.

9. Prince SA, Adamo KB, Hamel ME, Hardt J, Connor Gorber S, Tremblay M. A comparison of direct versus self-report measures for assessing physical activity in adults: a systematic review. Int J Behav Nutr Phys Act. 2008:5:56.

10. Prince SA, LeBlanc AG, Colley RC, Saunders TJ. Measurement of sedentary behaviour in population health surveys: a review and recommendations. PeerJ. 2017;5:e4130.

11. Healy GN, Clark BK, Winkler EAH, Gardiner PA, Brown WJ, Matthews CE. Measurement of adults' sedentary time in population-based studies. Am J Prev Med. 2011;41(2):216-27.

12. Prince SA, Butler GP, Roberts KC, Lapointe P, MacKenzie AM, Colley RC, et al. Developing content for national population health surveys: an example using a newly developed sedentary behaviour module. Arch Public Health. 2019;77:53.

13. Dowd KP, Szeklicki R, Minetto MA, Murphy MH, Polito A, Ghigo E, et al. A systematic literature review of reviews on techniques for physical activity measurement in adults: a DEDIPAC study. Int J Behav Nutr Phys Act. 2018;15(1):15.

14. Dall P, Coulter E, Fitzsimons C, Skelton D, Chastin S. TAxonomy of Selfreported Sedentary behaviour Tools (TASST) framework for development, comparison and evaluation of self-report tools: content analysis and systematic review. BMJ Open. 2017;7(4):e013844.

15. Grant PM, Ryan CG, Tigbe WW, Granat MH. The validation of a novel activity monitor in the measurement of posture and motion during everyday activities. Br J Sports Med. 2006;40(12):992-7.

16. Edwardson CL, Rowlands AV, Bunnewell S, Sanders J, Esliger DW, Gorely T, et al. Accuracy of Posture allocation algorithms for thigh- and waist-worn accelerometers. Med Sci Sports Exerc. 2016:48(6):1085-90.

17. Akerberg A, Koshmak G, Johansson A, Linden M. Heart rate measurement as a tool to quantify sedentary behavior. Studies Health Tech Info. 2015;211: 105-10.

18. Boudet G, Chausse P, Thivel D, Rousset S, Mermillod M, Baker JS, et al. How to measure sedentary behavior at work? Front. 2019;7(167).

19. Blanchard RA, Myers AM, Porter MM. Correspondence between selfreported and objective measures of driving exposure and patterns in older drivers. Accident Analysis Prev. 2010;42(2):523-9.

20. Kim H. Sedentary Behavior Intervention: Application of Contextual Information of Sedentary Behavior. Ann Arbor: Middle Tennessee State University; 2018.

21. Chastin SF, Granat MH. Methods for objective measure, quantification and analysis of sedentary behaviour and inactivity. Gait Posture. 2010;31(1):82-6.

22. Kozey-Keadle S, Libertine A, Lyden K, Staudenmayer J, Freedson PS. Validation of wearable monitors for assessing sedentary behavior. Med Sci Sports Exerc. 2011;43(8):1561-7.

23. Higgins JPT, Green S. Cochrane Handbook for Systematic Reviews of Interventions Version 5.1.0: The Cochrane Collaboration; 2011.

24. Aguilar-Farias N, Brown WJ, Olds TS, Peeters GMEE. Validity of self-report methods for measuring sedentary behaviour in older adults. J Sci Med Sport 2015;18(6):662-6

25. Chastin SFM, Dontje ML, Skelton DA, Cukic I, Shaw RJ, Gill JMR, et al. Systematic comparative validation of self-report measures of sedentary time 
against an objective measure of postural sitting (activPAL). Int J Behav Nutr Phys Act. 2018;15(1):21.

26. Chu AHY, Ng SHX, Koh D, Muller-Riemenschneider F. Domain-specific adult sedentary behaviour questionnaire (ASBQ) and the GPAQ single-item question: A reliability and validity study in an Asian population. Int J Environ Res Public Health. 2018;15(4):739.

27. Matthews CE, Kozey Keadle S, Moore SC, Schoeller DS, Carroll RJ, Troiano RP, et al. Measurement of active and sedentary behavior in context of large epidemiologic studies. Med Sci Sports Exerc. 2018;50(2):266-76.

28. Prince SA, Reid RD, Bernick J, Clarke AE, Reed JL. Single versus multi-item self-assessment of sedentary behaviour: A comparison with objectively measured sedentary time in nurses. J Sci Med Sport. 2018;21(9):925-9.

29. Rees-Punia E, Matthews CE, Evans EM, Keadle SK, Anderson RL, Gay JL, et al. Demographic-specific validity of the Cancer Prevention Study-3 Sedentary Time Survey. Med Sci Sports Exerc. 2019;51(1):41-8.

30. Ruiz-Casado A, Alejo LB, Santos-Lozano A, Soria A, Ortega MJ, Pagola I, et al. Validity of the Physical Activity Questionnaires IPAQ-SF and GPAQ for cancer survivors: Insights from a Spanish cohort. Int J Sports Med. 2016;37(12):979-85.

31. Dempsey PD, Thyfault JP. Chapter 5: Physiological Responses to Sedentary Behaviour. In: Leitzmann MF, Jochem C, Schmid D, editors. Sedentary Behaviour Epidemiology. Switzerland: Springer; 2018.

32. Buman MP, Winkler EA, Kurka JM, Hekler EB, Baldwin CM, Owen N, et al. Reallocating time to sleep, sedentary behaviors, or active behaviors: associations with cardiovascular disease risk biomarkers, NHANES 2005-2006. Am J Epidemiol. 2014;179(3):323-34.

33. Prince SA, Saunders TJ, Gresty K, Reid RD. A comparison of the effectiveness of physical activity and sedentary behaviour interventions in reducing sedentary time in adults: a systematic review and meta-analysis of controlled trials. Obes Rev. 2014;15(11):905-19.

34. Whiting PF, Rutjes AW, Westwood ME, Mallett S, Deeks JJ, Reitsma JB, et al. QUADAS-2: a revised tool for the quality assessment of diagnostic accuracy studies. Ann Intern Med. 2011;155(8):529-36.

35. Abraham TL. Comparison of accelerometers and a self-report record. Ann Arbor: Arizona State University; 2009.

36. Adams MA, Todd M, Kurka J, Conway TL, Cain KL, Frank LD, et al. Patterns of Walkability, Transit, and Recreation Environment for Physical Activity. Am J Prev Med. 2015;49(6):878-87.

37. Aguilar-Farias N, Leppe ZJ. Is a single question of the Global Physical Activity Questionnaire (GPAQ) valid for measuring sedentary behaviour in the Chilean population? J Sports Sci. 2017;35(16):1652-7.

38. Aittasalo M, Livson M, Lusa S, Romo A, Vähä-Ypyä H, Mänttäri A, et al. Moving to business - changes in physical activity and sedentary behavior after multilevel intervention in small and medium-size workplaces. BMC Public Health. 2017:17:1-14.

39. Alkahtani SA. Convergent validity: agreement between accelerometry and the Global Physical Activity Questionnaire in college-age Saudi men. BMC Res Notes. 2016;9(1):436.

40. Anjana RM, Sudha V, Lakshmipriya N, Subhashini S, Pradeepa R, Geetha L, et al. Reliability and validity of a new physical activity questionnaire for India. Int J Behav Nutr Phys Act. 2015;12(1):40.

41. Barone Gibbs B, Brach JS, Byard T, Creasy S, Davis KK, McCoy S, et al. Reducing sedentary behavior versus increasing moderate-to-vigorous intensity physical activity in older adults: A 12-week randomized, clinical trial. J Aging Health. 2017;29(2):247-67.

42. Barwais FA, Cuddihy TF, Washington T, Tomson LM, Brymer E. Development and validation of a new self-report instrument for measuring sedentary behaviors and light-intensity physical activity in adults. J Phys Act Health 2014;11(6):1097-104.

43. Benitez-Porres J, Delgado M, Ruiz JR. Comparison of physical activity estimates using International Physical Activity Questionnaire (IPAQ) and accelerometry in fibromyalgia patients: the Al-Andalus study. J Sports Sci. 2013;31(16):1741-52.

44. Biddle S, Edwardson C, Davies M, Gorely T, Khunti K, Nimmo M, et al. Agreement between accelerometer-determined sedentary time and self-report measures: Project STAND. J Sci Med Sport. 2012;15(SUPPL.1): S67-S8.

45. Biswas A, Oh Pl, Faulkner GE, Alter DA. A prospective study examining the influence of cardiac rehabilitation on the sedentary time of highly sedentary, physically inactive patients. Ann Phys Rehabil Med. 2018:61(4): 207-14
46. Blikman T, Stevens M, Reininga I, Van Den Akker-Scheek I, Bulstra SK. Testretest reliability and concurrent validity of the International Physical Activity Questionnaire (IPA Q) within patients after total hip arthroplasty. HIP Int. 2014:24(5):524.

47. Bond DS, Thomas JG, Unick JL, Raynor HA, Vithiananthan S, Wing RR. Selfreported and objectively measured sedentary behavior in bariatric surgery candidates. Surg Obes Relat Dis. 2013;9(1):123-8.

48. Bonn SE, Bergman P, Trolle Lagerros Y, Sjolander A, Balter K. A validation study of the Web-Based Physical Activity Questionnaire Active-Q against the GENEA accelerometer. JMIR Res Protoc. 2015;4(3):e86.

49. Bruening M, van Woerden I, Todd M, Brennhofer S, Laska MN, Dunton G. A mobile ecological momentary sssessment tool (devilSPARC) for nutrition and physical activity behaviors in college students: A validation study. J Med Internet Res. 2016;18(7):e209.

50. Bueno-Antequera J, Oviedo-Caro MA, Munguia-Izquierdo D. Sedentary behaviour patterns in outpatients with severe mental illness: a crosssectional study using objective and self-reported methods. The PsychiActive project. Psychiatr Res. 2017;255:146-52.

51. Busschaert C, De Bourdeaudhuij I, Van Holle V, Chastin SF, Cardon G, De Cocker K. Reliability and validity of three questionnaires measuring contextspecific sedentary behaviour and associated correlates in adolescents, adults and older adults. Int J Behav Nutr Phys Act. 2015;12:117.

52. Camhi SM, Crouter SE, Hayman LL, Lichtenstein AH, Must A. Physical activity and sedentary behavior in metabolically healthy obese young women. Circulation Conference: American Heart Association's Epidemiology and Prevention/Lifestyle and Cardiometabolic Health. 2015;131(SUPPL. 1).

53. Celis-Morales CA, Perez-Bravo F, Ibanez L, Salas C, Bailey ME, Gill JM. Objective vs. self-reported physical activity and sedentary time: effects of measurement method on relationships with risk biomarkers. PLoS One. 2012;7(5):e36345.

54. Cerin E, Barnett A, Cheung MC, Sit CHP, Macfarlane DJ, Chan WM. Reliability and validity of the IPAQ- $L$ in a sample of Hong Kong urban older adults: does neighborhood of residence matter? J Aging Phys Act. 2012;20(4):402-20.

55. Cerin E, Cain KL, Oyeyemi AL, Owen N, Conway TL, Cochrane T, et al. Correlates of agreement between accelerometry and self-reported physical activity. Med Sci Sports Exerc. 2016;48(6):1075-84.

56. Chapman JJ, Fraser SJ, Brown WJ, Burton NW. Physical activity and sedentary behaviour of adults with mental illness. J Sci Med Sport. 2016; 19(7):579-84.

57. Chasan-Taber L, Schmidt MD, Roberts DE, Hosmer D, Markenson G, Freedson PS. Development and validation of a pregnancy physical activity questionnaire. Med Sci Sports Exerc. 2004;36(10):1750-60.

58. Chastin SF, Culhane B, Dall PM. Comparison of self-reported measure of sitting time (IPAQ) with objective measurement (activPAL). Physiol Measure. 2014;35(11):2319-28.

59. Chau JY, Van Der Ploeg HP, Dunn S, Kurko J, Bauman AE. Validity of the occupational sitting and physical activity questionnaire. Med Sci Sports Exerc. 2012;44(1):118-25

60. Chau JY, van der Ploeg HP, Dunn S, Kurko J, Bauman AE. A tool for measuring workers' sitting time by domain: the Workforce Sitting Questionnaire. Br J Sports Med. 2011;45(15):1216-22.

61. Chau JY, Daley M, Dunn S, Srinivasan A, Do A, Bauman AE, et al. The effectiveness of sit-stand workstations for changing office workers' sitting time: results from the Stand@Work randomized controlled trial pilot. Int J Behav Nutr Phys Act. 2014;11:33-50.

62. Chinapaw MJM, Slootmaker SM, Schuit AJ, Van Zuidam M, Van Mechelen W. Reliability and validity of the activity questionnaire for adults and adolescents (AQuAA). BMC Med Res Method. 2009;9(1):58.

63. Clark BK, Lynch BM, Winkler EAH, Gardiner PA, Healy GN, Dunstan DW, et al. Validity of a multi-context sitting questionnaire across demographically diverse population groups: AusDiab3. Int J Behav Nutr Phys Act. 2015;12(1):148.

64. Clark BK, Pavey TG, Lim RF, Gomersall SR, Brown WJ. Past-day recall of sedentary time: Validity of a self-reported measure of sedentary time in a university population. J Sci Med Sport. 2016;19(3):237-41.

65. Clark BK, Thorp AA, AhW E, Gardiner PA, Healy GN, Owen N, et al. Validity of self-reported measures of workplace sitting time and breaks in sitting time. Med Sci Sports Exerc. 2011:43(10):1907-12.

66. Clark BK, Winkler E, Healy GN, Gardiner PG, Dunstan DW, Owen N, et al. Adults' past-day recall of sedentary time: Reliability, validity, and responsiveness. Med Sci Sports Exerc. 2013;45(6):1198-207. 
67. Clayton J. Comparison of Objectively and subjectively measured sedentary behavior in men with prostate cancer and a history of androgendeprivation therapy use. Ann Arbor: University of Washington; 2016.

68. Cleland CL, Hunter RF, Kee F, Cupples ME, Sallis JF, Tully MA. Validity of the global physical activity questionnaire (GPAQ) in assessing levels and change in moderate-vigorous physical activity and sedentary behaviour. BMC Public Health. 2014;14:1255

69. Cleland C, Ferguson S, Ellis G, Hunter RF. Validity of the International Physical Activity Questionnaire (IPAQ) for assessing moderate-to-vigorous physical activity and sedentary behaviour of older adults in the United Kingdom. BMC Med Res Method. 2018;18(1):176.

70. Clemes SA, David BM, Zhao Y, Han X, Brown W. Validity of two self-report measures of sitting time. J Phys Act Health. 2012;9(4):533-9.

71. Conroy DE, Maher JP, Elavsky S, Hyde AL, Doerksen SE. Sedentary behavior as a daily process regulated by habits and intentions. Health Psychol. 2013 32(11):1149-57.

72. Craig CL, Marshall AL, Sjostrom M, Bauman AE, Booth ML, Ainsworth BE, et al. International physical activity questionnaire: 12-Country reliability and validity. Med Sci Sports Exerc. 2003;35(8):1381-95.

73. Curry WB, Thompson JL. Comparability of accelerometer- and IPAQ-derived physical activity and sedentary time in South Asian women: A crosssectional study. Eur J Sport Sci. 2015;15(7):655-62.

74. Dahl-Petersen IK, Hansen AW, Bjerregaard P, Jkrgensen ME, Brage S. Validity of the international physical activity questionnaire in the arctic. Med Sci Sports Exerc. 2013;45(4):728-36.

75. De Cocker K, De Bourdeaudhuij I, Cardon G, Vandelanotte C, De Cocker PK. The effectiveness of a web-based computer-tailored intervention on workplace sitting: a randomized controlled trial. J Med Inter Res. 2016;18(5):e96-e109.

76. De Greef KP, Deforche BI, Ruige JB, Bouckaert JJ, Tudor-Locke CE, Kaufman JM, et al. The effects of a pedometer-based behavioral modification program with telephone support on physical activity and sedentary behavior in type 2 diabetes patients. Patient Educ Counsel. 2011;84(2):275-9.

77. Doyle C, Khan A, Burton N. Reliability and validity of a self-administered Arabic version of the global physical activity questionnaire (GPAQ-A). J Sports Med Phys Fitness. 2018;10:10.

78. Duncan MJ, Arbour-Nicitopoulos K, Subramaniapillai M, Remington G, Faulkner G. Revisiting the International Physical Activity Questionnaire (IPAQ): Assessing sitting time among individuals with schizophrenia. Psychiatr Res. 2019;271:311-8.

79. Dyrstad SM, Hansen BH, Holme IM, Anderssen SA. Comparison of selfreported versus accelerometer-measured physical activity. Med Sci Sports Exerc. 2014;46(1):99-106.

80. Ekblom Ö, Ekblom-Bak E, Bolam KA, Ekblom B, Schmidt C, Söderberg S, et al. Concurrent and predictive validity of physical activity measurement items commonly used in clinical settings--data from SCAPIS pilot study. BMC Public Health. 2015;15(1):1-10.

81. Ekelund U, Sepp H, Brage S, Becker W, Jakes R, Hennings M, et al. Criterion-related validity of the last 7-day, short form of the International Physical Activity Questionnaire in Swedish adults. Public Health Nutr. 2006;9(2):258-65.

82. Ellingson LD, Colbert LH, Cook DB. Physical activity is related to pain sensitivity in healthy women. Med Sci Sports Exerc. 2012;44(7):1401-6.

83. Elramli A Effectiveness of community based physical activity on step count and sedentary behaviour in people with rheumatoid arthritis within the first five years of diagnosis. Ann Arbor: University of Glasgow (United Kingdom); 2017.

84. Emadian A, Thompson J. A mixed-methods examination of physical activity and sedentary time in overweight and obese South Asian men living in the United Kingdom. Int J Environ Res Public Health. 2017;14(4):27.

85. English C, Healy GN, Coates A, Lewis L, Olds T, Bernhardt J. Sitting and activity time in people with stroke. Phys Ther. 2016;96(2):193-201.

86. Fitzsimons C, Kirk A, Murphy M, Mutrie N. Agreement between the IPAQlong weekday sitting item and the activPALTM activity monitor in Scottish adults. J Sci Med Sport. 2012;15(SUPPL.1):S295-S6.

87. Fitzsimons CF, Kirk A, Baker G, Michie F, Kane C, Mutrie N. Using an individualised consultation and activPAL [TM] feedback to reduce sedentary time in older Scottish adults: results of a feasibility and pilot study. Prev Med. 2013;57(5):718-20.

88. Fjeldsoe BS, Marshall AL, Miller YD. Measurement properties of the Australian women's activity survey. Med Sci Sports Exerc. 2009;41(5):1020-33.

89. Fowles JR, O'Brien MW, Wojcik WR, d'Entremont L, Shields CA. A pilot study: Validity and reliability of the CSEP-PATH PASB-Q and a new leisure time physical activity questionnaire to assess physical activity and sedentary behaviours. Appl Physiol Nutr Metab. 2017;42(6):677-80.

90. French SA, Harnack LJ, Toomey TL, Hannan PJ. Association between body weight, physical activity and food choices among metropolitan transit workers. Int J Behav Nutr Phys Act. 2007:4:52.

91. Gao Y, Cronin NJ, Nevala N, Finni T. Validity of long-term and short-term recall of occupational sitting time in Finnish and Chinese office workers. J Sport Health Sci. 2017.

92. Gardiner PA, Clark BK, Healy GN, Eakin EG, Winkler EAH, Owen N. Measuring older adults' sedentary time: Reliability, validity, and responsiveness. Med Sci Sports Exerc. 2011;43(11):2127-33.

93. Gennuso KP, Matthews CE, Colbert LH. Reliability and validity of 2 self-report measures to assess sedentary behavior in older adults. J Phys Act Health. 2015;12(5):727-32.

94. Gennuso KP, Thraen-Borowski KM, Gangnon RE, Colbert LH. Patterns of sedentary behavior and physical function in older adults. Aging Clin Exper Res. 2016;28(5):943-50.

95. Gibbs BB, King WC, Davis KK, Rickman AD, Rogers RJ, Wahed A, et al. Objective vs. Self-report sedentary behavior in overweight and obese young adults. J Phys Act Health. 2015;12(12):1551-7.

96. Gilbert AL, Lee J, Ma M, Semanik PA, DiPietro L, Dunlop DD, et al. Comparison of subjective and objective measures of sedentary behavior using the Yale Physical Activity Survey and accelerometry in patients with rheumatoid arthritis. J Phys Act Health. 2016;13(4):371-6.

97. Golubic R, May AM, Benjaminsen Borch K, Overvad K, Charles MA, Diaz MJ, et al. Validity of electronically administered Recent Physical Activity Questionnaire (RPAQ) in ten European countries. PLoS One. 2014;9(3): e92829.

98. Gomersall SR, Pavey TG, Clark BK, Jasman A, Brown WJ. Validity of a selfreport recall tool for estimating sedentary behavior in adults. J Phys Act Health. 2015;12(11):1485-91.

99. Gordon A. A theory-based pilot study to decrease sitting time in the workplace. Ann Arbor: Arizona State University; 2013.

100. Grimm EK, Swartz AM, Hart T, Miller NE, Strath SJ. Comparison of the IPAQShort Form and accelerometry predictions of physical activity in older adults. J Aging Phys Act. 2012;20(1):64-79.

101. Gupta N, Christiansen CS, Hanisch C, Bay H, Burr H, Holtermann A. Is questionnaire-based sitting time inaccurate and can it be improved? A cross-sectional investigation using accelerometer-based sitting time. BMJ Open. 2017;7(1):e013251.

102. Haakstad LA, Gundersen I, Bo K. Self-reporting compared to motion monitor in the measurement of physical activity during pregnancy. Acta Obstet Gynecol Scand. 2010;89(6):749-56.

103. Hagstromer M, Ainsworth BE, Oja P, Sjostrom M. Comparison of a subjective and an objective measure of physical activity in a population sample. J Phys Act Health. 2010;7(4):541-50.

104. Hansen AW, Dahl-Petersen I, Helge JW, Brage S, Gronbaek M, FlensborgMadsen T. Validation of an internet-based long version of the international physical activity questionnaire in danish adults using combined accelerometry and heart rate monitoring. J Phys Act Health. 2014;11(3):654-64.

105. Headley S, Hutchinson J, Wooley S, Dempsey K, Phan K, Spicer G, et al. Subjective and objective assessment of sedentary behavior among college employees. BMC Public Health. 2018;18(1).

106. Hekler EB, Buman MP, Haskell WL, Conway TL, Cain KL, Sallis JF, et al. Reliability and validity of CHAMPS self-reported sedentary-to-vigorous intensity physical activity in older adults. J Phys Act Health. 2012;9(2):225-36.

107. Herrmann SD, Heumann KJ, Der Ananian CA, Ainsworth BE. Validity and reliability of the Global Physical Activity Questionnaire (GPAQ). Measure Phys Educ Exerc Sci. 2013;17(3):221-35.

108. Hoos T, Espinoza N, Marshall S, Arredondo EM. Validity of the Global Physical Activity Questionnaire (GPAQ) in adult latinas. J Phys Act Health. 2012;9(5):698-705.

109. Hurtig-Wennlof A, Hagstromer M, Olsson LA. The International Physical Activity Questionnaire modified for the elderly: aspects of validity and feasibility. Public Health Nutr. 2010:1-8.

110. Hutchison K. Physical Activity in Fibromyalgia: Accelerometer versus selfreport. Ann Arbor: California State University, Fullerton; 2018.

111. Igelström H, Emtner M, Lindberg E, Åsenlöf P. Level of agreement between methods for measuring moderate to vigorous physical activity and sedentary time in people with obstructive sleep apnea and obesity. Phys Ther. 2013;93(1):50-9. 
112. Innerd P, Harrison R, Coulson M. Using open source accelerometer analysis to assess physical activity and sedentary behaviour in overweight and obese adults. BMC Public Health. 2018;18(1):543.

113. Ishii K, Shibata A, Kurita S, Yano S, Inoue S, Sugiyama T, et al. Validity and reliability of Japanese-language self-reported measures for assessing adults domain-specific sedentary time. J Epidemiol. 2018;28(3):149-55.

114. Jancey J, Tye M, McGann S, Blackford K, Lee AH. Application of the Occupational Sitting and Physical Activity Questionnaire (OSPAQ) to office based workers. BMC Public Health. 2014;14:762.

115. Kim Y, Welk GJ. The accuracy of the 24 -h activity recall method for assessing sedentary behaviour: the physical activity measurement survey (PAMS) project. J Sports Sci. 2017;35(3):255-61.

116. King AC, Hekler EB, Grieco LA, Winter SJ, Sheats JL, Buman MP, et al. Effects of three motivationally targeted mobile device applications on initial physical activity and sedentary behavior change in midlife and older adults: A randomized trial. PLoS One. 2016;11(6):e0156370.

117. Knell G, Gabriel KP, Businelle MS, Shuval K, Wetter DW, Kendzor DE. Ecological momentary assessment of physical activity: validation study. J Med Intern Res. 2017;19(7):e253.

118. Kohler S, Behrens G, Olden M, Baumeister SE, Horsch A, Fischer B, et al. Design and evaluation of a computer-based 24-hour physical activity recall (cpar24) instrument. J Med Intern Res. 2017;19(5):e186.

119. Kozey-Keadle S, Libertine A, Staudenmayer J, Freedson P. The feasibility of reducing and measuring sedentary time among overweight, non-exercising office workers. J Obes. 2012;2012:282303.

120. Kozo J, Kerr J, Saelens BE, Sallis JF, Conway TL, Cain K, et al. Sedentary behaviors of adults in relation to neighborhood walkability and income. Health Psychol. 2012;31(6):704-13.

121. Laeremans M, Dons E, Avila-Palencia I, Carrasco-Turigas G, Orjuela JP, Anaya E, et al. Physical activity and sedentary behaviour in daily life: A comparative analysis of the Global Physical Activity Questionnaire (GPAQ) and the SenseWear armband. PLoS One. 2017;12(5):e0177765.

122. Lagersted-Olsen J, Korshoj M, Skotte J, Carneiro IG, Sogaard K, Holtermann A. Comparison of objectively measured and self-reported time spent sitting. Int J Sports Med. 2014;35(6):534-40.

123. Larsson K, Kallings LV, Ekblom O, Blom V, Andersson E, Ekblom MM. Criterion validity and test-retest reliability of SED-GIH, a single item question for assessment of daily sitting time. BMC Public Health. 2019;19(1):17.

124. Legge A, Blanchard C, Hanly J. Physical activity and sedentary behaviour in patients with systemic lupus erythematosus and rheumatoid arthritis. J Rheumatol. 2017:44(6):880-1.

125. Lewis LK, Rowlands AV, Gardiner PA, Standage M, English C, Olds T. Small Steps: Preliminary effectiveness and feasibility of an incremental goal-setting intervention to reduce sitting time in older adults. Maturitas. 2016;85:64-70.

126. Lewis LS, Hernon J, Clark A, Saxton JM. Validation of the IPAQ against different accelerometer cut-points in older cancer survivors and adults at risk of cancer. J Aging Phys Activity. 2018;26(1):34-40.

127. Libertine A, Kozey-Keadle S, Freedson PS. Examining The accuracy of selfreported sitting time questionnaires compared to an objective measurement. Med Sci Sports Exerc. 2011;43:604-5.

128. Lopez-Rodriguez C, Laguna M, Gomez-Cabello A, Gusi N, Espino L, Villa G, et al. Validation of the self-report EXERNET questionnaire for measuring physical activity and sedentary behavior in elderly. Arch Gerontol Geriatr. 2017;69:156-61.

129. Loprinzi PD, Kane CJ. Exercise and cognitive function: A randomized controlled trial examining acute exercise and free-living physical activity and sedentary effects. Mayo Clinic Proceedings. 2015;90(4):450-60.

130. Lucas JM, Schmidt MD, Das BM, Evans EM. Agreement between selfreported and objective sitting times varies by day of week among college freshmen. Med Sci Sports Exerc. 2013;45:S323-S4.

131. Mader U, Martin BW, Schutz Y, Marti B. Validity of four short physical activity questionnaires in middle-aged persons. Med Sci Sports Exerc. 2006;38(7): 1255-66.

132. Maher JP, Conroy DE. Daily life satisfaction in older adults as a function of (in) activity. J Gerontol Series B. 2017;72(4):593-602

133. Marmeleira J, Laranjo L, Marques O, Batalha N. Criterion-related validity of the short form of the International Physical Activity Questionnaire in adults who are blind. J Visual Impairment Blindness. 2013;107(5):375-81.

134. Marshall AL, Miller YD, Burton NW, Brown WJ. Measuring total and domainspecific sitting: A study of reliability and validity. Med Sci Sports Exerc. 2010; 42(6):1094-102.
135. Marshall S, Kerr J, Carlson J, Cadmus-Bertram L, Patterson R, Wasilenko K, et al. Patterns of weekday and weekend sedentary behavior among older adults. J Aging Phys Activity. 2015;23(4):534-41.

136. Matsuo T, Sasai H, So R, Ohkawara K. Percentage-method improves properties of Workers' Sitting- and Walking-Time Questionnaire. J Epidemiol. 2016;26(8):405-12.

137. Matsuzaki M, Sullivan R, Ekelund U, Krishna KV, Kulkarni B, Collier T, et al. Development and evaluation of the Andhra Pradesh Children and Parent Study Physical Activity Questionnaire (APCAPS-PAQ): a cross-sectional study. BMC Public Health. 2016;16:48.

138. Matthews CE, Freedson PS. Field trial of a three-dimensional activity monitor: Comparison with self report. Med Sci Sports Exerc. 1995;27(7):1071-8.

139. Matthews CE, Keadle SK, Sampson J, Lyden K, Bowles HR, Moore SC, et al. Validation of a previous-day recall measure of active and sedentary behaviors. Med Sci Sports Exer. 2013:45(8):1629-38.

140. Matthews L, Hankey C, Penpraze V, Boyle S, Macmillan S, Miller S, et al. Agreement of accelerometer and a physical activity questionnaire in adults with intellectual disabilities. Prev Med. 2011;52(5):361-4.

141. Matton L, Wijndaele K, Duvigneaud N, Duquet W, Philippaerts R, Thomis $M$, et al. Reliability and validity of the flemish physical activity computerized questionnaire in adults. Res Q Exerc Sport. 2007;78(4): 293-306.

142. Mazzoni AS, Nordin K, Berntsen S, Demmelmaier I, Igelstrom H. Comparison between logbook-reported and objectively-assessed physical activity and sedentary time in breast cancer patients: an agreement study. BMC Sports Sci Med Rehabil. 2017:9:8.

143. McNeil J, Farris MS, Ruan Y, Merry H, Lynch BM, Matthews CE, et al. Effects of prescribed aerobic exercise volume on physical activity and sedentary time in postmenopausal women: A randomized controlled trial. Int J Behav Nutr Phys Act. 2018:15(1):27.

144. Melville CA, Boyle S, Miller S, Macmillan S, Penpraze V, Pert C, et al. An open study of the effectiveness of a multi-component weight-loss intervention for adults with intellectual disabilities and obesity. Br J Nutr. 2011;105(10):1553-62.

145. Menezes D, Laranjo L, Marmeleira J. Criterion-related validity of the short form of the international physical activity questionnaire in adults who are Deaf. Disabil Health J. 2017:10(1):33-8.

146. Mensah K, Maire A, Oppert JM, Dugas J, Charreire H, Weber C, et al. Assessment of sedentary behaviors and transport-related activities by questionnaire: a validation study. BMC Public Health. 2016;16:753.

147. Metcalf KM, Baquero Bl, Coronado Garcia ML, Francis SL, Janz KF, Laroche $\mathrm{HH}$, et al. Calibration of the global physical activity questionnaire to Accelerometry measured physical activity and sedentary behavior. BMC Public Health. 2018;18(1):412.

148. Meyer JD. Physical Activity, Exercise and BDNF in Depressed Patients - A Study of the Acute Effects of Exercise Intensity on Mood. Ann Arbor: The University of Wisconsin - Madison; 2015.

149. Moran F Perceived barriers, facilitators and patterns of physical activity of older old adults living in assisted retirement accommodation. Ann Arbor: Western Sydney University (Australia); 2016.

150. Moss SJ, Czyz SH. Level of agreement between physical activity levels measured by ActiHeart and the International Physical Activity Questionnaire in persons with intellectual disability. Disabil Rehabil. 2018:40(3):360-6.

151. Mumu SJ, Ali L, Barnett A, Merom D. Validity of the global physical activity questionnaire (GPAQ) in Bangladesh. BMC Public Health. 2017;17(1):650

152. Murillo-Rabago I, Armendariz-Anguiano AL, Jimenez-Cruz A, Bacardi-Gascon M. Validity of the international physical activity questionnaire among mexican adults. Obes. 2010;2:S132-S3.

153. O'Neill B, McDonough SM, Wilson JJ, Bradbury I, Hayes K, Kirk A, et al. Comparing accelerometer, pedometer and a questionnaire for measuring physical activity in bronchiectasis: A validity and feasibility study? Resp Res. 2017;18(1):16.

154. Oostdam N, van Mechelen W, Van Poppel M. Validation and responsiveness of the AQUAA for measuring physical activity in overweight and obese pregnant women. J Sci Med Sport. 2013;16(5):412-6.

155. Otten JJ, Littenberg B, Harvey-Berino JR. Relationship between Self-report and an objective measure of television-viewing time in adults. Obes. 2010; 18(6):1273-5.

156. Oviedo-Caro MA, Bueno-Antequera J, Munguia-Izquierdo D. Measuring sedentary behavior during pregnancy: comparison between self-reported and objective measures. Matern Child Health J. 2018;22(7):968-77. 
157. Oyeyemi AL, Umar M, Oguche F, Aliyu SU, Oyeyemi AY. Accelerometerdetermined physical activity and its comparison with the international physical activity questionnaire in a sample of Nigerian adults. PLoS One. 2014;9(1):e87233.

158. Pedersen SJ, Kitic CM, Bird ML, Mainsbridge CP, Cooley PD. Is self-reporting workplace activity worthwhile? Validity and reliability of occupational sitting and physical activity questionnaire in desk-based workers. BMC Public Health. 2016;16(1):836.

159. Pedisic Z, Bennie JA, Timperio AF, Crawford DA, Dunstan DW, Bauman AE, et al. Workplace Sitting Breaks Questionnaire (SITBRQ): an assessment of concurrent validity and test-retest reliability. BMC Public Health. 2014;14:1249.

160. Peters TM, Shu XO, Moore SC, Xiang YB, Yang G, Ekelund U, et al. Validity of a physical activity questionnaire in Shanghai. Med Sci Sports Exerc. 2010; 42(12):2222-30.

161. Pinto B, Dunsiger S, Stein K. Does a peer-led exercise intervention affect sedentary behavior among breast cancer survivors? Psycho-Oncol. 2017; 26(11):1907-13.

162. Powell JL, Agne AA, Willig A, Cherrington AL. Self-report versus objective measures of physical activity in overweight/obese latina immigrants in alabama. Obes. 2011;1:S201-S2.

163. Prince SA, Reid RD, Reed JL. Comparison of self-reported and objectively measured levels of sitting and physical activity and associations with markers of health in cardiac rehabilitation patients. Eur J Prev Cardiol. 2019; 26(6):653-6

164. Riviere F, Widad FZ, Speyer E, Erpelding ML, Escalon H, Vuillemin A. Reliability and validity of the French version of the global physical activity questionnaire. J Sport Health Sci. 2018;7(3):339-45.

165. Roman-ViÑAs B, Serra-Majem L, HagstrÖMer M, Ribas-Barba L, SjÖStrÖM M, Segura-Cardona R. International Physical Activity Questionnaire: Reliability and validity in a Spanish population. Eur J Sport Sci. 2010;10(5):297-304.

166. Rosenberg DE, Norman GJ, Wagner N, Patrick K, Calfas KJ, Sallis JF. Reliability and validity of the Sedentary Behavior Questionnaire (SBQ) for adults. J Phys Act Health. 2010;7(6):697-705.

167. Rosenberg DE, Gell NM, Jones SMW, Renz A, Kerr J, Gardiner PA, et al. The feasibility of reducing sitting time in overweight and obese older adults. Health Educ Behav. 2015;42(5):669-76.

168. Rosenberg DE, Bellettiere J, Gardiner PA, Villarreal VN, Crist K, Kerr J. Independent associations between sedentary behaviors and mental, cognitive, physical, and functional health among older adults in retirement communities. J Gerontol Series A. 2016;71(1):78-83.

169. Ruiz-Casado A, Brea L, Soria A, Ortega MJ, Cebolla H, Fiuza C, et al. Concurrent validity and accuracy of the shortform of international physical activity questionnaire (SF-IPAQ) in a population of Spanish cancer survivors. J Clin Oncol Conf. 2015;33(15 SUPPL. 1).

170. Ryan CG, McDonough S, Kirwan JP, Leveille S, Martin DJ. An investigation of association between chronic musculoskeletal pain and cardiovascular disease in the Health Survey for England (2008). Eur J Pain. 2014;18(5):740-50.

171. Ryan DJ, Wullems JA, Stebbings GK, Morse Cl, Stewart CE, OnambelePearson GL. Reliability and validity of the international physical activity questionnaire compared to calibrated accelerometer cut-off points in the quantification of sedentary behaviour and physical activity in older adults. PLoS One. 2018;13(4):e0195712.

172. Ryde GC, Gorely T, Jepson R, Gray C, Shepherd A, Mackison D, et al. How active are women who play bingo: a cross-sectional study from the Well!Bingo project. BMC Women Health. 2017;17:1-8.

173. Sasaki JE, Motl RW, McAuley E. Validity of the Marshall Sitting Questionnaire in people with multiple sclerosis. J Sports Sci. 2018:1-7.

174. Schaller A, Rudolf K, Dejonghe L, Grieben C, Froboese I. Influencing factors on the overestimation of self-reported physical activity: a cross-sectional analysis of low back pain patients and healthy controls. BioMed Res Int. 2016:2016:1497213.

175. Scheers T, Philippaerts R, Lefevre J. Assessment of physical activity and inactivity in multiple domains of daily life: A comparison between a computerized questionnaire and the SenseWear Armband complemented with an electronic diary. Int J Behav Nutr Phys Act. 2012;9:71.

176. Segura-Jimenez V, Munguia-Izquierdo D, Camiletti-Moiron D, AlvarezGallardo IC, Ortega FB, Ruiz JR, et al. Comparison of the International Physical Activity Questionnaire (IPAQ) with a multi-sensor armband accelerometer in women with fibromyalgia: The al-andalus project. Clin Exper Rheumatol. 2013;31(SUPPL.79):094-101.
177. Shadyab AH, Macera CA, Shaffer RA, Jain S, Gallo LC, LaMonte MJ, et al. Associations of accelerometer-measured and self-reported sedentary time with leukocyte telomere length in older women. Am J Epidemiol. 2017; 185(3):172-84.

178. Shuval K, Kohl HW 3rd, Bernstein I, Cheng D, Pettee Gabriel K, Barlow CE, et al. Sedentary behaviour and physical inactivity assessment in primary care: the Rapid Assessment Disuse Index (RADI) study. Br J Sports Med. 2014:48(3):250-5.

179. Simpson K, Parker B, Capizzi J, Thompson P, Clarkson P, Freedson P, et al. Validity and reliability question 8 of the Paffenbarger Physical Activity Questionnaire among healthy adults. J Phys Act Health. 2015;12(1):116-23.

180. Stolberg CR, Mundbjerg LH, Bladbjerg EM, Funch-Jensen P, Gram B, Juhl CB. Physical training following gastric bypass: effects on physical activity and quality of life-a randomized controlled trial. Qual Life Res. 2018;27(12):3113-22.

181. Sudholz B, Ridgers ND, Mussap A, Bennie J, Timperio A, Salmon J. Reliability and validity of self-reported sitting and breaks from sitting in the workplace. J Sci Med Sport. 2018;21(7):697-701.

182. Sushames AJ, Edwards AM, Mein JK, Sinclair KM, Maguire GP. Utility of fieldbased techniques to assess Indigenous Australians' functional fitness and sedentary time. Public Health. 2015;129(12):1656-61.

183. Sweatt SK, Willig AL, Agne AA, Powell JL, Cherrington AL. Physical activity patterns of Latina immigrants living in Alabama. J Racial Ethnic Health Disparities. 2015;2(3):365-72.

184. Terada T, Sexsmith JR. Determination of young adults' sedentary time with a multisensory activity monitor and activity log diary. Tech Health Care. 2015;23(6):835-45.

185. Toledo MJ, Hekler E, Hollingshead K, Epstein D, Buman M. Validation of a smartphone app for the assessment of sedentary and active behaviors. JMIR Mhealth Uhealth. 2017:5(8):e119.

186. Umstattd Meyer MR, Baller SL, Mitchell SM, Trost SG. Comparison of 3 accelerometer data reduction approaches, step counts, and 2 self-report measures for estimating physical activity in free-living adults. J Phys Act Health. 2013;10(7):1068-74.

187. Unick JL, Lang W, Tate DF, Bond DS, Espeland MA, Wing RR. Objective estimates of physical activity and sedentary time among young adults. J Obes. 2017;2017:9257564.

188. Urda JL, Larouere B, Verba SD, Lynn JS. Comparison of subjective and objective measures of office workers' sedentary time. Prev Med Rep. 2017:8:163-8.

189. Van Cauwenberg J, Van Holle V, De Bourdeaudhuij I, Owen N, Deforche B. Older adults' reporting of specific sedentary behaviors: validity and reliability. BMC Public Health. 2014;14:734.

190. Van Der Ploeg HP, Merom D, Chau JY, Bittman M, Trost SG, Bauman AE. Advances in population surveillance for physical activity and sedentary behavior: Reliability and validity of time use surveys. Am J Epidemiol. 2010; 172(10):1199-206

191. Van Dyck D, Cardon G, Deforche B, Owen N, Sallis JF, De Bourdeaudhuij I. Neighborhood walkability and sedentary time in Belgian adults. Am J Prev Med. 2010;39(1):25-32

192. Van Dyck D, Cardon G, Deforche B, De Bourdeaudhuij I. IPAQ interview version: convergent validity with accelerometers and comparison of physical activity and sedentary time levels with the self-administered version. J Sports Med Phys Fitness. 2015;55(7-8):776-86.

193. van Nassau F, Chau JY, Lakerveld J, Bauman AE, van der Ploeg HP. Validity and responsiveness of four measures of occupational sitting and standing. Int J Behav Nutr Phys Act. 2015;12(1):144.

194. Vandezande AM. Associations of levels and types of physical activity and sedentary behavior with total and abdominal fat in overweight and obese adults. Ann Arbor: San Diego State University; 2014.

195. Vandoni M, Buzzachera C, Ottobrini S, Correale L, Borrelli P, Berzolari F, et al. Perceived and objectively measured physical activity in high school students: is there any link between aerobic fitness, psychological responses and acute exercise? Sport Sci Health. 2017;13(1):157-64.

196. Vanroy C, Vanlandewijck Y, Cras P, Feys H, Truijen S, Michielsen M, et al Is a coded physical activity diary valid for assessing physical activity level and energy expenditure in stroke patients? PLoS One. 2014;9(6): e98735.

197. Veitch W, Climie R, Gabbe B, Dunstan D, Owen N, Ekegren C. Validation of two physical activity and sedentary behaviour questionnaires in orthopaedic trauma patients. J Sci Med Sport. 2018;21(Supplement 1):S85. 
198. Visser M, Koster A. Development of a questionnaire to assess sedentary time in older persons - a comparative study using accelerometry. BMC Geriatrics. 2013;13(1):80.

199. Wanner M, Probst-Hensch N, Kriemler S, Meier F, Autenrieth C, Martin BW. Validation of the long international physical activity questionnaire: Influence of age and language region. Prev Med Rep. 2016;3:250-6.

200. Wanner M, Hartmann C, Pestoni G, Martin BW, Siegrist M, Martin-Diener E. Validation of the Global Physical Activity Questionnaire for self-administration in a European context. BMJ Open Sport Exerc Med. 2017;3(1):e000206.

201. Waters CN, Er Pei L, Chu AHY, Ng SHX, Chia A, Yee Wei L, et al. Assessing and understanding sedentary behaviour in office-based working adults: a mixed-method approach. BMC Public Health. 2016;16(1):1-11.

202. Watson ED, Micklesfield LK, Van Poppel MNM, Norris SA, Sattler MC, Dietz P. Validity and responsiveness of the Global Physical Activity Questionnaire (GPAQ) in assessing physical activity during pregnancy. PLoS One. 2017; 12(5):e0177996.

203. Welch WA, Lloyd GR, Awick EA, Siddique J, McAuley E, Phillips SM Measurement of physical activity and sedentary behavior in breast cancer survivors. J Community Supportive Oncol. 2018;16(1):e21-e9.

204. Whitfield GP, Gabriel KKP, Kohl IHW. Assessing sitting across contexts: Development of the multicontext sitting time questionnaire. Res Q Exerc Sport. 2013;84(3):323-8.

205. Wick K, Faude O, Schwager S, Zahner L, Donath L. Deviation between selfreported and measured occupational physical activity levels in office employees: effects of age and body composition. Int Arch Occup Environ Health. 2016;89(4):575-82.

206. Wijndaele K, DEB I, Godino JG, Lynch BM, Griffin SJ, Westgate K, et al. Reliability and validity of a domain-specific last 7-d sedentary time questionnaire. [Erratum appears in Med Sci Sports Exerc. 2014 Sep;46(9): 1869]. Med Sci Sports Exerc. 2014;46(6):1248-60.

207. Yi S, Bartley K, Firestone M, Eisenhower D. Self-reported sitting time using a two-question method is a good measure of sedentary behavior: Findings in the New York city adult population. Circulation Conference: American Heart Association's Epidemiology and Prevention/Nutrition, Physical Activity, and Metabolism. 2014;129(SUPPL. 1).

208. Yu CA, Rouse P, Veldhuijzen Van Zanten J, Metsios G, Ntoumanis N, Kitas G, et al. Associations between objective and self-reported physical activity data in rheumatoid arthritis patients. Annals of the Rheumatic Diseases Conference: Annual European Congress of Rheumatology of the European League Against Rheumatism, EULAR. 2014;73(SUPPL. 2).

209. Boyle T, Lynch BM, Courneya KS, Vallance JK. Agreement between accelerometer-assessed and self-reported physical activity and sedentary time in colon cancer survivors. Supportive Care Cancer. 2015;23(4):1121-6.

210. Hur SA, Guler SA, Khalil N, Camp PG, Guenette JA, Swigris JJ, et al. Minimal important difference for physical activity and validity of the International Physical Activity Questionnaire in interstitial lung disease. Ann Am Thorac Soc. 2019;16(1):107-15.

211. Cicchetti DV. Guidelines, criteria, and rules of thumb for evaluating normed and standardized assessment instruments in psychology. Psychol Assess. 1994;6(4):284-90.

212. Saunders TJ, Chaput J-P, Tremblay MS. Sedentary behaviour as an emerging risk factor for cardiometabolic diseases in children and youth. Can J Diabetes. 2014;38(1):53-61.

213. Colley RC, Butler G, Garriguet D, Prince SA, Roberts KC. Comparison of selfreported and accelerometer-measured physical activity in Canadian adults. Health Rep. 2018;29(12):3-15.

214. Atkin AJ, Gorely T, Clemes SA, Yates T, Edwardson C, Brage S, et al. Methods of measurement in epidemiology: sedentary behaviour. Int J Epidemiol. 2012:41(5):1460-71.

215. Stamatakis E, Davis M, Stathi A, Hamer M. Associations between multiple indicators of objectively-measured and self-reported sedentary behaviour and cardiometabolic risk in older adults. Prev Med. 2012;54(1):82-7.

216. Ku P-W, Steptoe A, Liao Y, Hsueh M-C, Chen L-J. A cut-off of daily sedentary time and all-cause mortality in adults: a meta-regression analysis involving more than 1 million participants. BMC Med. 2018;16(1):74

217. Chau JY, Grunseit AC, Chey T, Stamatakis E, Brown WJ, Matthews CE, et al. Daily sitting time and all-cause mortality: a meta-analysis. PLoS One. 2013; 8(11):e80000.

218. Garcia JM, Duran AT, Schwartz JE, Booth JN 3rd, Hooker SP, Willey JZ, et al. Types of sedentary behavior and risk of cardiovascular events and mortality in Blacks: The Jackson Heart Study. J Am Heart Assoc. 2019;8(13):e010406.
219. Cleland VJ, Schmidt MD, Dwyer T, Venn AJ. Television viewing and abdominal obesity in young adults: is the association mediated by food and beverage consumption during viewing time or reduced leisure-time physical activity? Am J Clin Nutr. 2008;87(5):1148-55.

220. Lowry R, Wechsler H, Galuska DA, Fulton JE, Kann L. Television viewing and its associations with overweight, sedentary lifestyle, and insufficient consumption of fruits and vegetables among US high school students: differences by race, ethnicity, and gender. J Sch Health. 2002;72(10):413-21.

\section{Publisher's Note}

Springer Nature remains neutral with regard to jurisdictional claims in published maps and institutional affiliations.
Ready to submit your research? Choose BMC and benefit from:

- fast, convenient online submission

- thorough peer review by experienced researchers in your field

- rapid publication on acceptance

- support for research data, including large and complex data types

- gold Open Access which fosters wider collaboration and increased citations

- maximum visibility for your research: over $100 \mathrm{M}$ website views per year

At BMC, research is always in progress.

Learn more biomedcentral.com/submissions 